\title{
Carbonyl Reduction and Biomass: a Case Study of Sustainable Catalysis
}

\author{
Alain You Li ${ }^{\dagger}$, Audrey Moores*† \\ ${ }^{\dagger}$ Centre for Green Chemistry and Catalysis, Department of Chemistry, McGill University, \\ 801 Sherbrooke Street West, Montreal, QC, H3A 0B8, Canada.*Audrey.moores@mcgill.ca
}

\section{Graphical abstract}

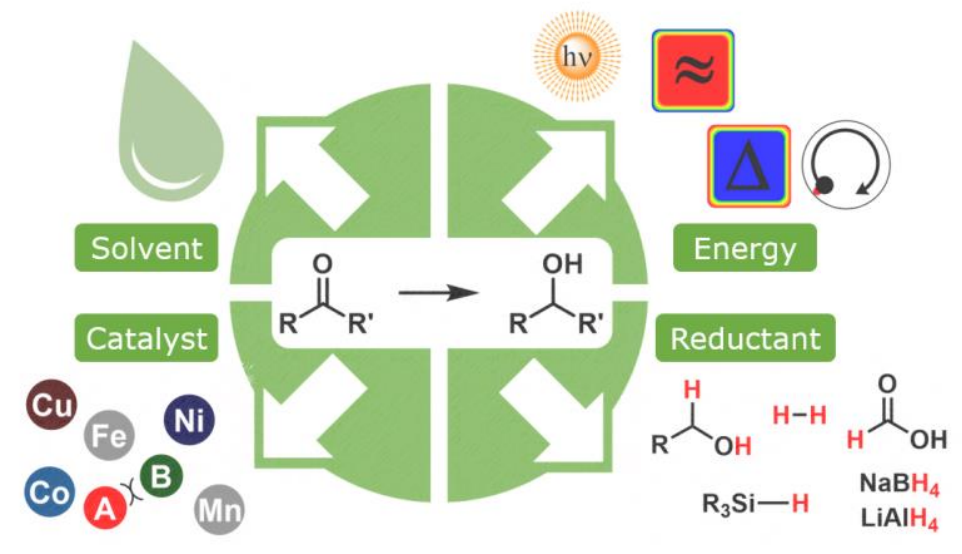

\begin{abstract}
Catalysis plays a major role at mitigating the environmental impact of the chemical industry, drastically cutting its energy and material consumption. For this perspective, we have chosen $\mathrm{C}=\mathrm{O}$ reduction in the context of biomass as a benchmark reaction to introduce and illustrate essential aspects of green catalysis. We first covered the most used $\mathrm{C}=\mathrm{O}$ hydrogenation substrates made from biomass. Then, we looked at alternative energy sources to convective heating, discussed the use of greener solvents and reductants, and listed a few precious metalfree catalytic systems. Finally we looked at various hydrogen sources, including bio-sourced ones. In particular, we emphasized the use of metrics in order to quantify the actual impact of these innovations.
\end{abstract}

\section{Keywords}

Catalysis - Hydrogenation - Biomass - Solvent - Energy

\section{Synopsis (1 sentence 20 words)}

$\mathrm{C}=\mathrm{O}$ reduction of biomass was used as a benchmark to give an overview of recent developments in catalysis 


\section{Introduction}

From the inception of green chemistry, catalysis has been considered a key tool to achieve a more sustainable chemical industry, and was coined a "pillar of green chemistry", in addition to being one of its 12 principles. ${ }^{1}$ Indeed catalysis offers the possibility to positively impact a chemical process in many different ways, including lowering energy and materials inputs, increasing conversion and selectivity, thus improving upon separation and purification and favoring less dangerous and toxic reagents. In a quarter century of green chemistry research, ${ }^{2}$ catalysis has enabled some of its finest developments. Catalysis has proven a particularly appealing strategy towards tackling the grand challenge of biomass conversion to useful chemicals and fuels.

Catalytic reduction is among the most important chemical transformations in volume in industry and are routinely employed at all scales of chemical production. ${ }^{3}$ Reduction is a particularly crucial process in the context of biomass transformation, since the lignocellulosic material is oxygen rich, with a key feature on carbonyl reduction. ${ }^{4}$ Indeed, most biomassderived molecules are naturally $\mathrm{C}=\mathrm{O} / \mathrm{C}-\mathrm{O}$-rich, in contrast to petroleum-based chemicals. ${ }^{5}$

Hydrogen gas is often considered an ideal reducing agent both in terms of cost and atom economy. Indeed, hydrogenation has been largely explored in academia, with the first catalytic example reported in 1874 for olefin hydrogenation. ${ }^{6}$ It has become a powerful tool for key processes in the industry, such as the Haber-Bosch process, the Fischer-Tropsch synthesis, or oil refining. ${ }^{7}$ Despite its advantages, the use of $\mathrm{H}_{2}$ gas may be problematic in some settings because of its flammability and the need for pressurization. On the other side of the spectrum, in the pharmaceutical industry, the most common reducing agents used are $\mathrm{LiAlH}_{4}$ and $\mathrm{NaBH}_{4}$. These inorganic salts are particularly reactive toward carbonyls, and have been successfully implemented in large-scale processes (>100 mol scale) ${ }^{8}$ Noyori-type catalysts are, on their end, most used for asymmetric prochiral ketone reduction. ${ }^{9}$

In the context of biomass upgrading, $\mathrm{H}_{2}$ is commonly used as the reducing agent, in conjunction with a catalyst. Platinum group metals (PGMs) such as $\mathrm{Pd}, \mathrm{Ru}$ as both homogeneous and heterogeneous systems are commonly investigated for their activity and selectivity. These come with their own drawbacks: low abundance, ${ }^{10}$ high toxicity, ${ }^{11}$ and recycling issues. ${ }^{12}$ Thus a lot of research efforts are dedicated to the development of heterogeneous catalysts and/or the use of earth abundant metals in the context of biomass upgrading. ${ }^{13}$ Transfer hydrogenation methodologies have also been explored. ${ }^{4}$ 
For this perspective, we have chosen $\mathrm{C}=\mathrm{O}$ reduction in the context of biomass as a benchmark reaction to introduce and illustrate essential aspects of green catalysis. We have reviewed some of the most used $\mathrm{C}=\mathrm{O}$ hydrogenation substrates taken from biomass (1). We looked at alternative energy sources and solvent used in this context (2 and 3). We then explored the development of greener catalysts based on nonprecious metals (4), before exploring the importance of the hydrogen sources, with a special attention to bio-sourced ones (5). Throughout the manuscript, attempts were made to highlight how green chemistry metrics were used to shed light on the relevance of the reported methods. Green metrics are an essential means to bring rational comparison and perspective and their use is encouraged. ${ }^{14}$ The field of biomass catalytic reduction is the center of a lot of scientific attention and as such, the reader is encouraged to consult recent reviews of this field. ${ }^{4}$

\section{$\mathrm{C}=\mathrm{O}$ hydrogenation substrates}

Benzylic carbonyls (namely benzaldehyde and acetophenone) are commonly reported as model substrates for the $\mathrm{C}=\mathrm{O}$ hydrogenation reaction, due to their high reactivity and ease of handling, and are easy first steps in the exploration of a new reduction catalyst. Unsurprisingly reduction of biomass-derived platform molecules, in particular levulinic acid (LA) or 5hydroxymethylfurfural (5-HMF), is intensely explored as well. ${ }^{15}$ They can be made from acidic treatment of glucose or cellulose, and for both, pilot plants dedicated to their production from biomass have been built. ${ }^{16-17}$ Their reduction products are useful building blocks available for further functionalization, showing the key role of $\mathrm{C}=\mathrm{O}$ hydrogenation in chemical industry. Typically, selectivity is an important aspect, with carbonyl hydrogenation being less favored compared to nitroarene, alkyne and alkene hydrogenation (Error! Reference source not found.). ${ }^{18}$

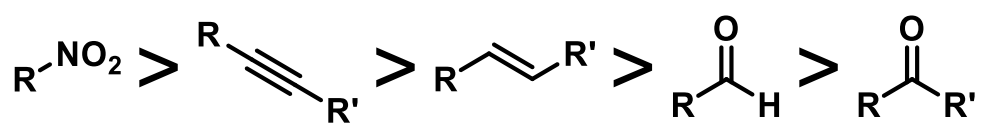

Scheme 1. Usual reactivity trends in hydrogenation.

Another industrially relevant and bio-based target is citral. It contains one $\mathrm{C}=\mathrm{O}$ and two unsaturated $\mathrm{C}=\mathrm{C}$ bonds with various steric hindrances, making for challenging selectivity issues as well. In the context of using biomass as substrate for hydrogenation, it is important to note that there are still open questions about the sustainability of such resources. One must also take in account the origin of a chemical, as well as its fate after use. Life Cycle Analysis (LCA) comes in as a powerful tool to thoroughly evaluate a chemical's environmental impact through 
different scopes (e.g. ozone depletion, fossil fuel consumption, ecotoxicity, global warming, etc...). ${ }^{19}$ For instance, Montazeri et al. compared the LCA of the production of lignin-based tert-butyl catechol (TBC) and fossil fuel-based TBC. ${ }^{20}$ They showed that the use of dichloromethane as an extraction solvent in the former route heavily penalized its ozone depletion burden by a 1000-fold factor while overall both routes had the same global warming impact $\left(1.25 \mathrm{~kg}_{\mathrm{CO} 2} / \mathrm{kg}_{\mathrm{TBC}}\right)$. More work on this field is certainly important to provide context in some of the chemistry described in this review. ${ }^{21} 22$

\section{Levulinic acid}

LA forms $\gamma$-valerolactone (GVL) upon hydrogenation and subsequent cyclization (Scheme 2). ${ }^{23} \mathrm{GVL}$ is useful in itself as a fuel additive or solvent, ${ }^{24}$ and can be further reduced to 2-methyltetrahydrofuran (2-MeTHF) for similar purposes. It can be further converted to $\alpha$ methylene- $\gamma$-valerolactone (MeMBL) using formaldehyde, and serves as a methyl methacrylate upgrade in its polymerisation. ${ }^{25}$ Indeed, it increases the glass transition temperature of the resulting copolymer by $100^{\circ} \mathrm{C}$ compared to pure poly-methyl methacrylate. GVL can also reversibly convert to pentenoic acid (PEA), ${ }^{26}$ which can be further hydrogenated to pentanoic acid (PA). All these intermediates can be decarboxylated or used as chemical building blocks or fuel additives. ${ }^{27}$ Another closely related pathway to carbonyl hydrogenation is reductive amination, from which LA can form 2-pyrrolidinone derivatives. ${ }^{28}$ In practice, since the carboxylate function in LA can poison catalyst surfaces, ethyl levulinate (EL) and butyl levulinate (BL) can be used instead. Both of them can be easily converted to GVL by $\mathrm{C}=\mathrm{O}$ reduction. ${ }^{29}$

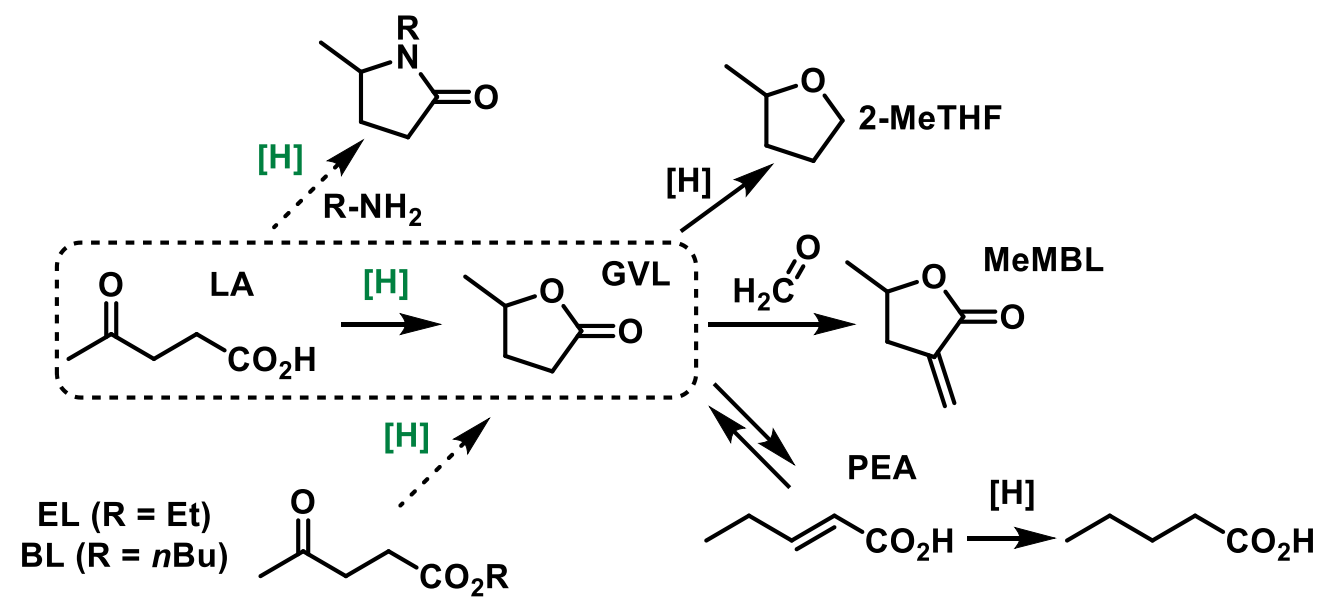

Scheme 2. LA hydrogenation and further upgrade pathways.

\section{Furfural and 5-Hydroxymethylfurfural}


Furfural (FF) and 5-HMF are both furan derivatives that can be generated from the acidcatalyzed dehydration of biomass-derived xylose and glucose respectively. ${ }^{30}$ Both of them constitute promising substitutes building blocks derived from petrochemicals in the production of plastics and fine chemicals. ${ }^{31}$

The reduction of 5-HMF into 2,5-dihydroxymethylfuran (DHMF) has been covered by $\mathrm{Hu}$ et al. (Scheme 3). ${ }^{32}$ This symmetrical diol can be directly used as a co-monomer, for example with succinic acid to form poly(2,5-furandimethylene succinates) (PFS). ${ }^{33}$ It can also be etherified using various short chain alcohols to form 2,5-bis(alkoxymethyl)furan (BAMF) that can be used as fuel additives. ${ }^{34}$ Lastly, it can be re-arranged into 6-hydroxy-6-methyl-4enyl-2H-pyran-3-one (HMEPO), an intermediate for the synthesis of sugar analogues and compounds with excellent biological activities. ${ }^{35}$ Furfural can be reduced to furfuryl alcohol (FFA), that can be mostly converted to fuel additives (2-methylfuran and 2methyltetrahydrofuran) and solvents (tetrahydrofurfuryl alcohol). ${ }^{36}$ FFA can also be hydrogenated then isomerized into cyclopentanone, an important chemical intermediate to produce insecticides and rubber chemicals. ${ }^{37}$

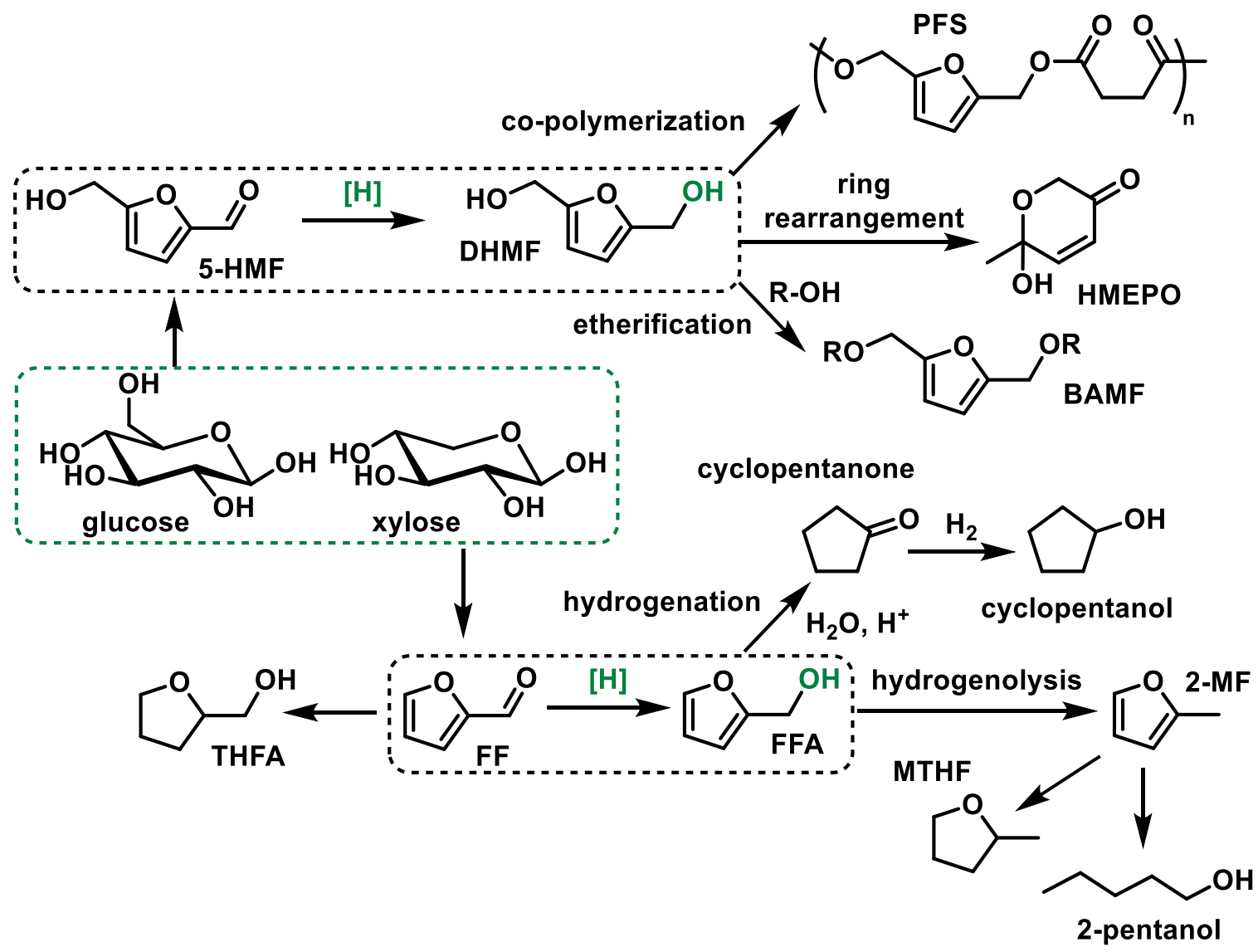


Scheme 3. FF and 5-HMF hydrogenation and further upgrade pathways.

\section{Citral}

Citral, a monoterpenoid containing three unsaturations $(1 \mathrm{C}=\mathrm{O}$ bond and $2 \mathrm{C}=\mathrm{C}$ bonds), is distilled from essential oils such as lemongrass oil. It is responsible for the 'citrus effect' in perfumes and other flavored consumer goods, and widely used as such. It can be cyclized into other flavors such as menthol. ${ }^{38}$ Stolle et al. have identified citral hydrogenation as a challenging process, considering the selectivity issue stemming from the presence of three double bonds (making up to 8 potential products, Scheme 4). ${ }^{39}$ Carefully designed catalytic systems, composed of transition metals Ag, Ru or Os, combined with acidic promoters such as $\mathrm{In}_{2} \mathrm{O}_{3}, \mathrm{CeO}_{2}$ or $\mathrm{MgO}$, have enabled breakthrough toward improved reactivity and selectivity in favor of $\mathrm{C}=\mathrm{O}$ reduction. ${ }^{40}$

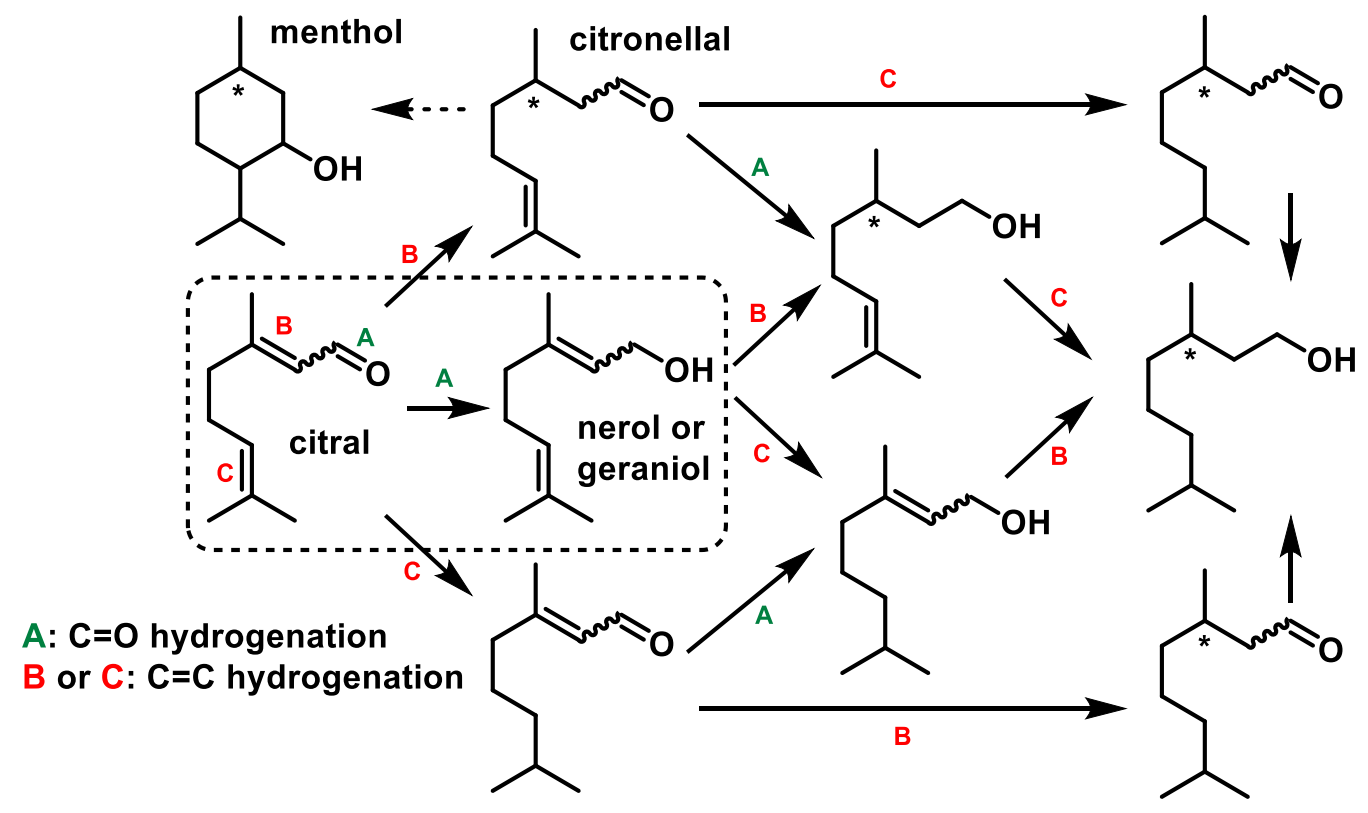

Scheme 4. Citral hydrogenation selectivity issues (each hydrogenation pathway is indicated above the arrows).

\section{Alternative energy sources}

As outlined by Varma et al., a number of alternative energy inputs have been successfully applied to both organic chemistry and material synthesis. ${ }^{41}$ These all constitute an effort towards improving the efficiency of a reaction from an energetic perspective. Indeed, most organic reactions are conducted using convective heating, a slow method relying on convection currents and thermal conductivity to transfer energy to the reaction mixture. ${ }^{42}$

\section{Microwave heating}


Microwave irradiations occur in the $0.3-300 \mathrm{GHz}$ range and are typically used in chemistry at $2.45 \mathrm{GHz}$. This frequency corresponds to a wavelength of $12.24 \mathrm{~cm}$, and photon energy of $0.0016 \mathrm{eV}$, thus lower than Brownian motion. ${ }^{43}$ Instead, microwave dielectric heating relies on the capacity of the reaction medium to absorb microwave energy and dissipate it into heat through a dipole oscillating field alignment then friction phenomenon, along with an ionic conduction mechanism. ${ }^{44}$ In the case of conducting or semi-conducting materials such as metals, ohmic heating phenomenon can be involved as well. ${ }^{45}$ Overall, this results in a faster and more homogeneous heating of the reaction medium, and has been successfully applied to both organic chemistry and nano-material synthesis. ${ }^{41}$ By drastically reducing reaction time, ${ }^{46}$ energy efficiency is increased compared to conventional heating $(>30 \%) .{ }^{47}$

Early examples (1997-2002) of the use of microwave heating were straightforward transposition of known transfer hydrogenation reactions, namely $\mathrm{NaBH}_{4}$ reduction ${ }^{48-49}$ and the Meerwein-Ponndorf-Verley reaction. ${ }^{50-51}$ Later, the advent of microwave reactors adapted to organic reactions led to better controlled chemical processes. In 2008, Varma and co-workers reported $\mathrm{Ni}$ supported on a magnetite support, using dopamine as a linker $\left(\mathrm{Ni} @ \mathrm{Fe}_{3} \mathrm{O}_{4}\right) .{ }^{52} \mathrm{Later}$ on, they published a similar report using Ru supported on a magnetite core with a silica shell $\left(\mathrm{Ru} @ \mathrm{Fe}_{3} \mathrm{O}_{4}\right) .{ }^{53}$ Yoshida et al. also reported the preparation of $\mathrm{Cu}$ supported on hexagonal mesoporous silica (Cu@HMS) under microwave. ${ }^{54}$ These three catalysts share similar performances for the transfer hydrogenation of ketones using $i \mathrm{PrOH}$ in microwave, requiring a base $(\mathrm{NaOH}$ or $\mathrm{KOH})$, and showing high recyclability with no metal leaching (Scheme 5A). Gowda et al. reported the use of non-noble metal carbonyls (Fe, Mo, Co, W) as in situ precursors to nanocatalysts for LA hydrogenation to GVL (Scheme 5B). ${ }^{55}$ While under conventional heating $\mathrm{HCO}_{2} \mathrm{H} / \mathrm{NEt}_{3}$ reductant was required, EtOH under microwave served as both solvent and reductant in the reaction with a drastic reaction time decrease (from $48 \mathrm{~h}$ to $20 \mathrm{~min})$. 
A)

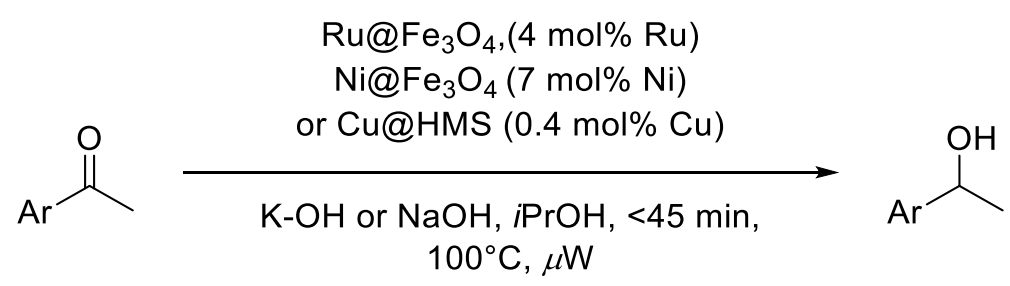

B)<smiles>CC(=O)CCC(=O)O</smiles>
levulinic acid thermal conditions: $\mathrm{HCO}_{2} \mathrm{H} / \mathrm{Et}_{3} \mathrm{~N}, \mathrm{H}_{2} \mathrm{O}, 48 \mathrm{~h}$ $89 \%$ yield

microwave conditions: $\mathrm{KOH}, \mathrm{EtOH}, 20 \mathrm{~min}$ $82 \%$ yield

Scheme 5. Microwave heating for catalytic carbonyl transfer hydrogenation.

\section{Mechanochemistry}

20 million tons of organic solvents are produced every year, and make up to $85 \%$ in mass of waste emission for the synthesis of active pharmaceutical ingredients. ${ }^{56}$ These large quantities are required not only to ensure the homogenization of a chemical mixture, but also to perform extraction, purification and cleaning purposes. ${ }^{57} \mathrm{~A}$ mechanochemical reaction is defined by the IUPAC as 'a chemical reaction that is induced by the direct absorption of mechanical energy", through impact and/or shearing with a milling apparatus. ${ }^{58}$ Furthermore, the absence of solvent can favor an acceleration of reaction rate through high concentration, and offers an opportunity to solve substrate solubility issues.

In fact, mechanochemical reactions are the oldest and simplest techniques used in history, as mortars and pestles have been well documented throughout the history of food and medicine preparation. $\mathrm{NaBH}_{4}$-induced carbonyl reduction has been readily transposed to mechanochemistry, starting with an early report by Toda et al. using manual grinding and improved by Cho et al. with the addition of acids (benzoic acid, $p$-toluene sulfonic acid or $\left.\mathrm{H}_{3} \mathrm{BO}_{3}\right){ }^{59-60}$ Mack et al. reported the first mechanochemical reduction of carbonyls using a ball-mill mixer, with a further mechanistical study by Naimi-Jamal et al. ${ }^{61-62}$ Notably, the addition of $\mathrm{LiCl}$ salt could induce the in situ formation of $\mathrm{LiBH}_{4}$ that is reactive enough to reduce esters. Lastly, Solà et al. reported a sustainable route for the synthesis of Fluoxetine (Prozac), using microwave heating and ball-milling. ${ }^{63}$ In their second step, ball-milling with $\mathrm{NaBH}_{4}$ was successfully applied for the reduction of an aminoketone (Scheme 6A). Our group contributed to mechanochemical reduction of carbonyls. In this case the source of hydrogen was not conventional $\mathrm{NaBH}_{4}$, but a solid waste from the silicone industry, 
polymethylhydrosiloxane (PMHS), activated by tert-butyl ammonium fluoride on silica (TBAF@ $\mathrm{SiO}_{2}$ ) as a catalyst. ${ }^{64}$ Notably, 5-HMF was reduced through the fractioned addition of PMHS in three portions, reaching a 69\% yield (Scheme 6B). Interestingly separation of product and reagent was simplified compared to the solution-based method.
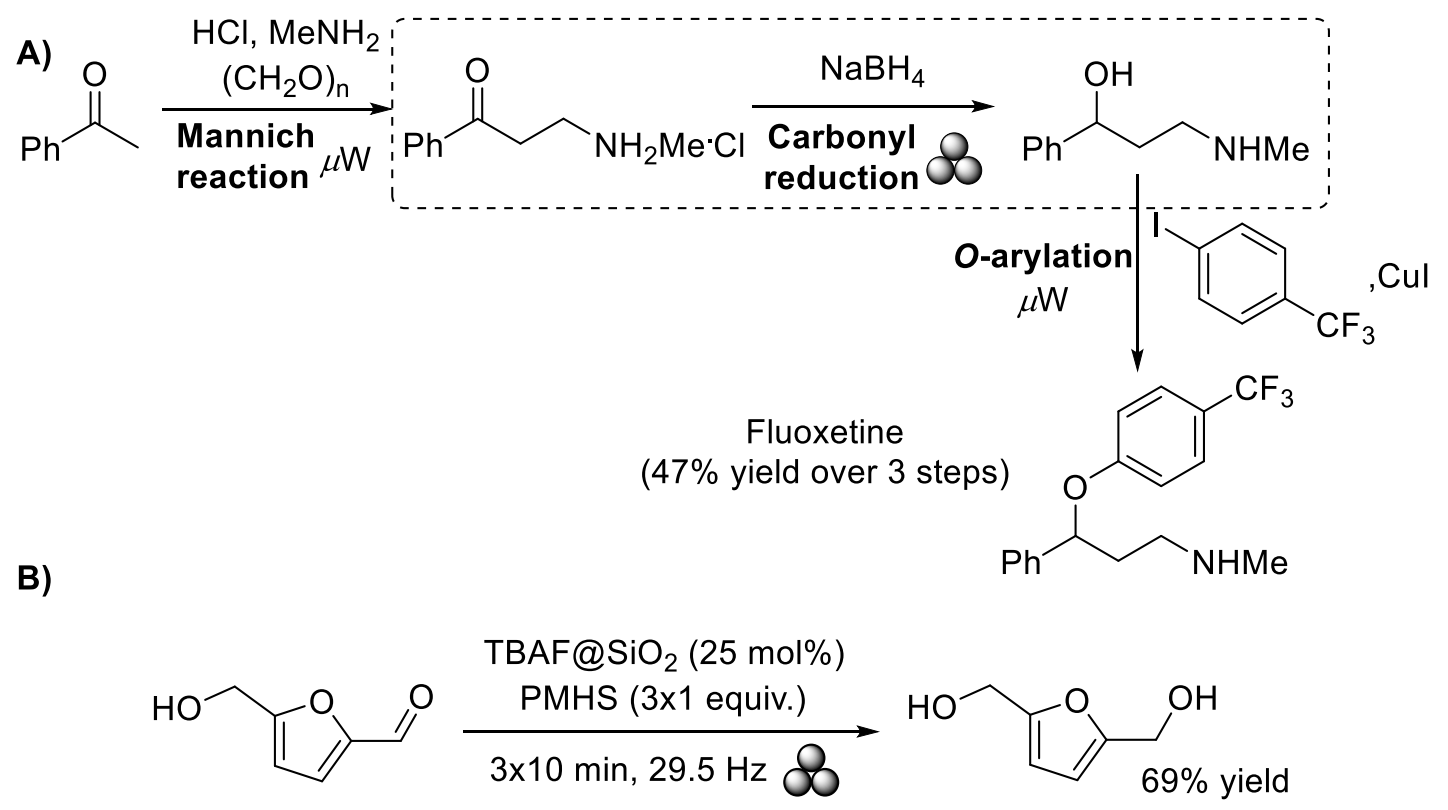

Scheme 6. A) Sustainable synthesis of Fluoxetine B) Mechanochemical reduction of 5-HMF.

\section{Photochemistry}

Photocatalysis is a mode of catalysis where a dye is used to absorb light and cause chemical activation of substrate molecules, usually through the separation of $\mathrm{e}^{-} / \mathrm{h}^{+}$pairs. Early carbonyl hydrogenation photocatalysts consisted in light absorption semi-conductors such as CdS NPs, ${ }^{65} \mathrm{TiO}_{2} \mathrm{NPs},{ }^{66-67}$ or poly(p-phenylene) (PPP), ${ }^{68}$ using sacrificial electron donors such as $\mathrm{Et}_{3} \mathrm{~N}, i \operatorname{Pr}_{2} \mathrm{NH}, \beta$-mercaptoethanol and lactic acid (Scheme 7A). Sharma et al. reported $\mathrm{Ru}$ supported on graphitic carbon nitride $\left(\mathrm{Ru} @ \mathrm{~g}-\mathrm{C}_{3} \mathrm{~N}_{4}\right)$, using and short chain alcohols as reductants $(\mathrm{EtOH}, n \mathrm{PrOH}, i \mathrm{PrOH}) .{ }^{69} \mathrm{C}_{3} \mathrm{~N}_{4}$ is a visible light absorbing heterogeneous semiconducting material, that could be recycled up to 6 times (Scheme 7B). König et al. reported the synergistic activity of proflavine (PF) as a dye and a Rh complex for aldehyde reduction, functioning under blue light $(455 \mathrm{~nm})$ and being compatible with flow conditions (Scheme 7C). ${ }^{70}$ Call et al. eventually showed that an earth abundant, oxygen- and water-stable photocatalytic tandem based on $\mathrm{Cu}$ and $\mathrm{Co}$ was suitable as well. ${ }^{71}$ Although outside the scope of this perspective, the field of $\mathrm{CO}_{2}$ reduction by photoactivation has been particularly dynamic 
in the past few years, and the reader is directed towards recent reviews for more details. ${ }^{72} 73$ Interestingly there, water is used as a $\mathrm{H}_{2}$ source, via a water splitting scheme.
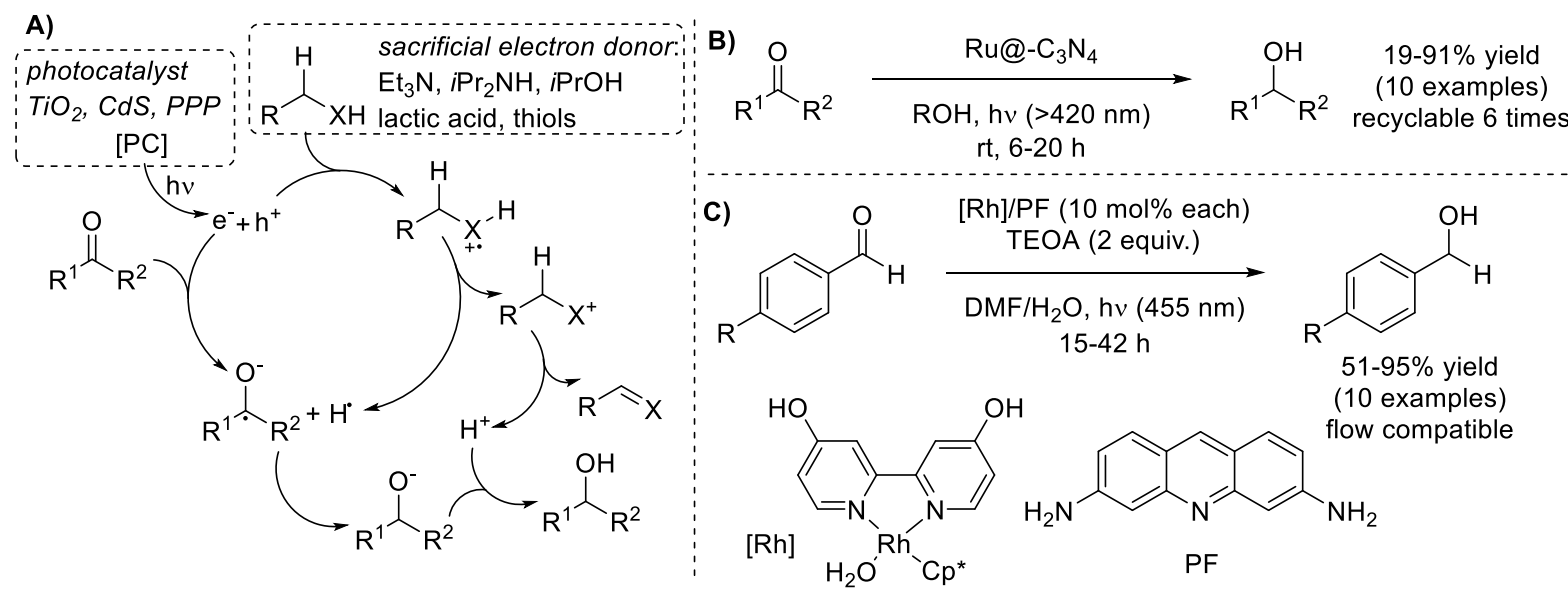

Scheme 7. A) General scheme for photo-induced reduction of carbonyls. B) $\mathrm{Ru} @ \mathrm{~g}-\mathrm{C}_{3} \mathrm{~N}_{4}$ as a photocatalyst $\mathrm{C}$ ) $[\mathrm{Rh}] / \mathrm{PF}$ as a photocatalytic duet.

Plasmonic catalysis. Plasmonic photocatalysis is based on visible-light absorption of metal NPs resulting from their localized surface plasmon resonances (LSPR). ${ }^{74}$ Indeed, visible light can enable the collective oscillation of the valence electrons of coinage metal NPs ( $\mathrm{Au}, \mathrm{Ag}$, $\mathrm{Cu}$ ) and $\mathrm{Al}$ NPs, allowing them to act as catalyst through the generation of high-energy electrons. Hao et al. used Au NPs supported on $\mathrm{SiC}(\mathrm{Au} @ \mathrm{SiC})$ as plasmonic catalysts for the $\mathrm{C}=\mathrm{O}$-selective transfer hydrogenation of $\alpha, \beta$-unsaturated carbonyls under visible light (Scheme 8). ${ }^{75}$ Similarly, our group exploited the same phenomenon with $\mathrm{Ag}$ nanocubes (Ag NC, Scheme 8). ${ }^{76}$ Under mild $\mathrm{H}_{2}$ pressure (1 bar), especially for Ag NPs, Landry et al. successfully reduced a range of 12 carbonyls including aliphatic ketones and cinnamaldehyde at the $\mathrm{C}=\mathrm{O}$ position. Citral was selectively reduced into geraniol in high yields (79\%).

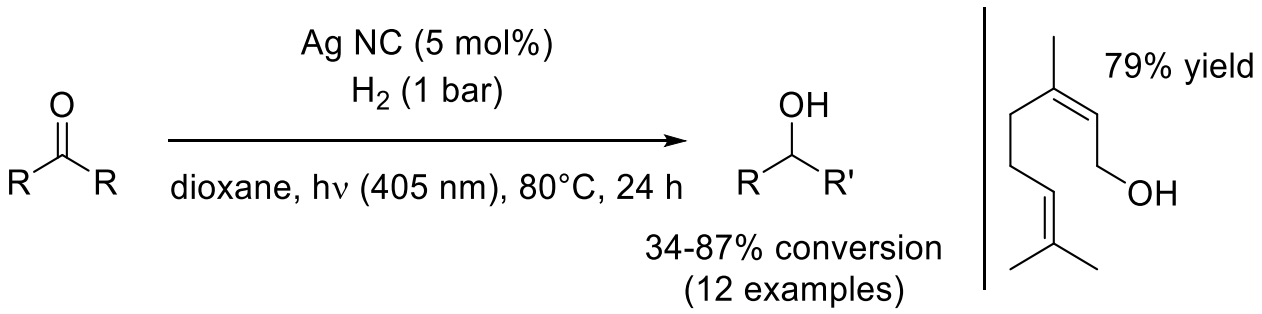

Scheme 8. Plasmon-driven selective reduction of carbonyls using Ag NC.

\section{Solvents}

A number of organic solvents are harmful, toxic and environmentally damaging. However, they are crucial in most organic reactions to dissolve chemical compounds, enable heat 
dispersion and ensure proper mass transfer. Substituting them or alleviating their use is no simple task, as many factors (such as safety, separation cost, viscosity, solvation properties, chemical stability) must be taken in account to evaluate their impact. ${ }^{77}$ As stated earlier, switching to solvent-free processes is a viable option, whether it is in liquid or solid phase. Not using solvents allows higher reaction rates due to higher concentration (for bimolecular reactions and beyond), as well as lower costs. However, low diffusion rates and heat dispersion issues due to higher mixture viscosity can be encountered in solvent-free conditions. Ultimately, the impact of a solvent on the performance of a reaction or on the economics of a process are the governing parameters, respectively in academia and industry.

In 2010, Prof. Jessop conducted a survey aiming at identifying solvents causing the least environmental damage. Most parameters pointed at supercritical $\mathrm{CO}_{2}$, water and carefully chosen traditional organic solvents (these 3 categories added up to $75 \%$ of the total poll responses). ${ }^{78}$ This puts in perspective the importance given to Ionic Liquids (ILs), in particular in the Green Chemistry journal where $50 \%$ of the papers describe results with this class of solvents. These high-end and very polar solvents come with a heavy synthetic cost, although they can be used to treat usually insoluble biomass polymers such as lignin and cellulose. ${ }^{79}$ In the context of $\mathrm{C}=\mathrm{O}$ reduction in particular, ILs featured poorly as they favor $\mathrm{C}=\mathrm{C}$ reduction instead. ${ }^{80-81}$ Finally, Prof. Jessop listed a few scientific challenges in green solvent development, such as developing more diverse solvents in terms of polarity and hydrogen bond donor capacity (cf. Kamlet-Taft diagram), while taking in account the synthetic route and safety parameters. For instance, developing a sustainable low boiling-point polar aprotic solvent is still highly desirable. Besides, solvent choice is now made easier via the published guides produced by pharmaceutical companies (Pfizer, ${ }^{82}$ GSK, ${ }^{83-84}$ Solvay ${ }^{85}$ ) and the ACS Green Chemistry Institute (ACS-GCI) Pharmaceutical Roundtable. ${ }^{86}$ In a holistic approach, these aggregated several key parameters such as safety and waste treatment, conveniently helping the process chemist in choosing the most appropriate solvent.

\section{$\mathrm{H}_{2} \mathrm{O}$}

For a long time, $\mathrm{H}_{2} \mathrm{O}$ as a solvent has been deemed as unsuitable for organic chemistry, despite reactions in nature taking place as aqueous enzymatic processes. Breslow et al. made a first breakthrough in 1980 by showing that Diels-Alder cyclization of cyclopentadiene with butanone proceeded 700 times faster faster in $\mathrm{H}_{2} \mathrm{O}$ than in iso-octane. ${ }^{87}$ In the context of carbonyl reduction, the authors exploited $\mathrm{H}_{2} \mathrm{O}$ as well to tune selectivity to the most 
hydrophobic substrate. Shen et al. analyzed by surface vibrational spectroscopy $\mathrm{H}_{2} \mathrm{O}$-hexane and $\mathrm{H}_{2} \mathrm{O}$-air interfaces, showing that in all cases, about $25 \%$ of surface water molecules at the hydrophobic interface have one dangling - $\mathrm{OH}$ group, protruding into the hydrophobic layer without making hydrogen bonds. ${ }^{88}$ Thus, these dangling bonds have been hypothesized to decrease activation barriers, effectively accelerating chemical reactions where the transition state benefits from hydrogen bonding with $\mathrm{H}_{2} \mathrm{O} .{ }^{89}$

Surfactants can be employed to maximize water/organic layer interface, while using minimal amounts of organic solvents and metal catalysts (up to ppm levels)..$^{90}$ Overall, switching to micellar catalysis drastically reduces the E-factor of a reaction initially conducted in organic media, up to a tenth of its original value. ${ }^{91}$ Surfactants have been applied for great effect on metal-catalyzed asymmetric ketone transfer hydrogenation using $\mathrm{HCO}_{2} \mathrm{Na}$, based on $\left[\mathrm{Cp}{ }^{*} \mathrm{Ru}(\mathrm{TsDPEN})\right]-$ like complexes grafted on a sodium dodecyl sulfate (SDS) surfactant (Scheme 9A). ${ }^{92-95}$

Alternatively, metal complexes can be made recyclable by making them water-soluble. ${ }^{96}$ Typically, this is done by the grafting of hydrophilic groups on the ligand, such as sulfonate groups on triphenylphosphine (TPPTS). ${ }^{97}$ Grosselin et al. explored this ligand with Ru and Rh for the hydrogenation of $\alpha, \beta$-unsaturated aldehydes in $\mathrm{H}_{2} \mathrm{O} .{ }^{98}$ Interestingly, the metals were respectively selective towards $\mathrm{C}=\mathrm{O}$ and $\mathrm{C}=\mathrm{C}$ reduction (Scheme 9B). More recent developments were applied to LA hydrogenation, using water-soluble phenanthroline ligands (BPhDS, Scheme 9C).$^{99-100}$ 


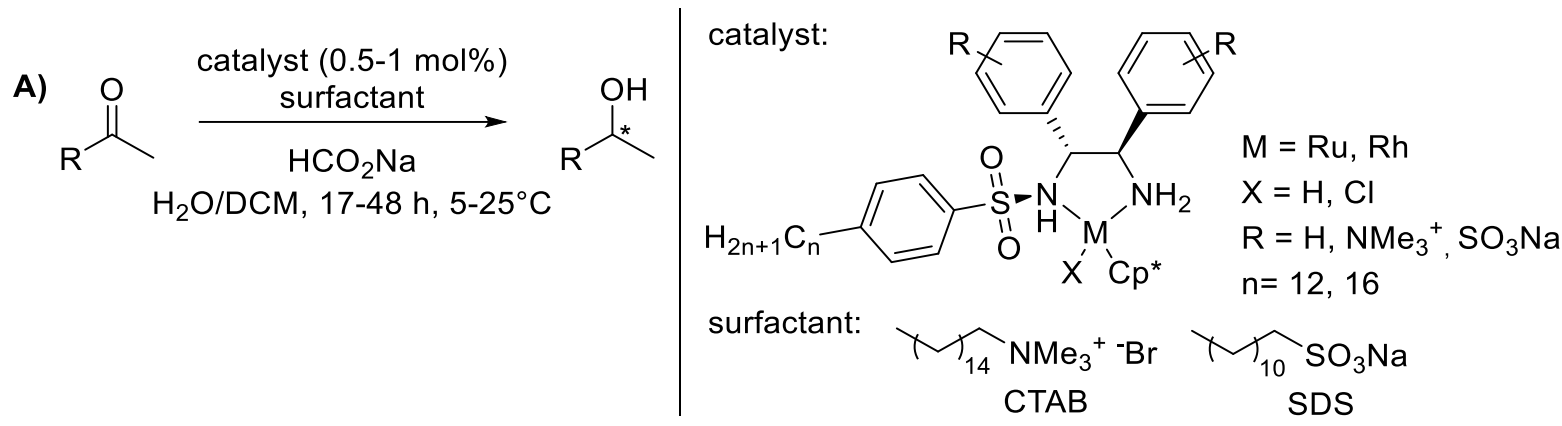

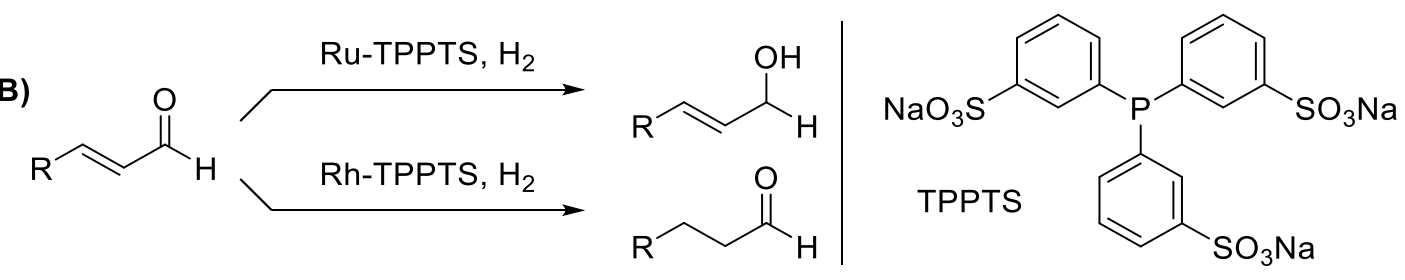

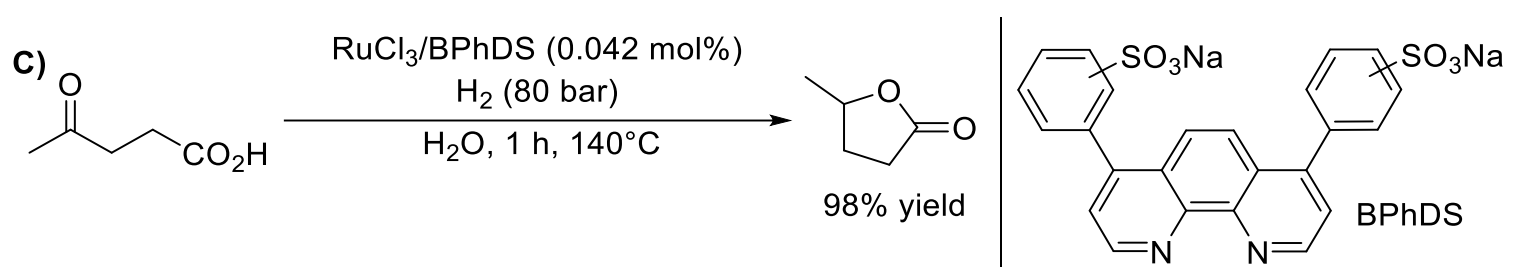

Scheme 9. Approaches for carbonyl reduction in $\mathrm{H}_{2} \mathrm{O}$ : A) Using surfactants B) Using watersoluble catalysts C) Application to LA hydrogenation.

\section{Supercritical carbon dioxide}

Supercritical $\mathrm{CO}_{2}\left(\mathrm{sCO}_{2}\right)$ has seen great applications in hydrogenations due its mild critical point ( $304 \mathrm{~K}, 73.8 \mathrm{~atm})$, the innocuous nature and non-flammability of $\mathrm{CO}_{2}$, the ease of post-synthesis removal, and notably the full miscibility of $\mathrm{H}_{2}$ in $\mathrm{sCO}_{2} \cdot{ }^{101-103}$ In comparison, at ambient temperature and atmospheric pressure the molar solubility of $\mathrm{H}_{2}$ in various solvents is as following: $0.8 .10^{-3} \mathrm{M}$ in $\mathrm{H}_{2} \mathrm{O}, 1.95 \times 10^{-4} \mathrm{M}$ in EtOH and $2.64 \times 10^{-4} \mathrm{M}$ in acetone. ${ }^{104}$

Furthermore, $\mathrm{sCO}_{2}$ promotes selective $\mathrm{C}=\mathrm{O}$ reduction due to the dielectric constant of $\mathrm{CO}_{2}$ increasing with pressure, making it a polar solvent. ${ }^{105-103,106}$ Arai et al. exploited this property for citral hydrogenation, attaining $\mathrm{C}=\mathrm{O}$ and $\mathrm{C}=\mathrm{C}$ reduction selectivity with $\mathrm{Ru}$ and $\mathrm{Pd}$ respectively (65\% and 75\% selectivity, Scheme 10A). ${ }^{107}$ Interestingly, Li et al. exploited $\mathrm{sCO}_{2}$ as a medium for $\mathrm{Zn} / \mathrm{H}_{2} \mathrm{O}$-mediated reduction of aldehydes, through in situ $\mathrm{H}_{2} \mathrm{O}$ splitting (Scheme 10B). ${ }^{108}$ Harada et al. also reported a catalyst-free carbonyl reduction process in supercritical $i \mathrm{PrOH}\left(508 \mathrm{~K}, 48\right.$ bar). ${ }^{109-110}$ 
A)<smiles>CC(C)=CCCC(C)=CC=O</smiles>

B)<smiles>[R]C=O</smiles>
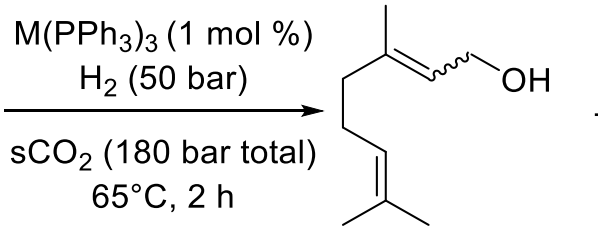

$\mathrm{M}=\mathrm{Ru}$ $95 \%$ conversion $65 \%$ selectivity

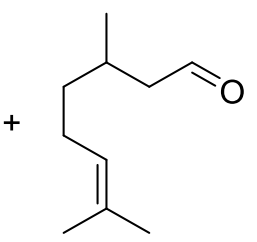

$\mathrm{M}=\mathrm{Pd}$ $100 \%$ conversion $75 \%$ selectivity

$\mathrm{Zn}$ dust (1.25 equiv.)

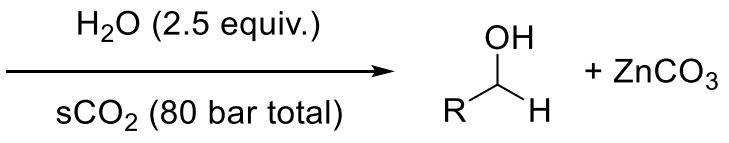

$65^{\circ} \mathrm{C}, 6-24 \mathrm{~h}$

(6 examples)

Scheme 10. $\mathrm{sCO}_{2}$ for: A) citral $\mathrm{C}=\mathrm{O}$ reduction $\left.\mathrm{B}\right) \mathrm{Zn} / \mathrm{H}_{2} \mathrm{O}$-induced carbonyl reduction.

\section{Catalysts}

Catalysis relies on the principle that a catalyst does not get consumed during a reaction, but rather remains active to engage into further reactive cycles. Practically though, their life time can be limited by inactivation, or simply by the difficulty of their separation from the product and reuse. Not only it is problematic from an economical perspective, it causes toxicity issues in the final product, both for PGMs and more abundant metals $(\mathrm{Ni}, \mathrm{Cu}) .{ }^{111}$ One option, which is favored in industry, is the use of heterogeneous catalysts due to their easy recyclability, although they tend to feature lower activity and selectivity compared to homogeneous complexes. In high-added value synthesis such as pharmaceutical compounds, the use of PGM-containing homogeneous catalysts remains essential. Nonetheless, efforts towards diminishing metal loading or shifting to base metals are on the rise. ${ }^{112}$

\section{Base-metal catalysts}

Iron. Fe has seen tremendous development in the field of carbonyl hydrogenation, through its cooperation with specifically tailored ligands or supports for $\mathrm{H}_{2}$ activation. ${ }^{113}$ A prime example is the Knölker complex, where Fe is assisted by a cyclopentadienone ligand for the splitting of $\mathrm{H}_{2}{ }^{114-117}$ Casey and Guan were the first to show its potency for carbonyl hydrogenation (Scheme 11A), ${ }^{118}$ followed by Fleischer et al. ${ }^{119}$ In parallel, Morris et al. reported a family of Fe-PNNP pincer complexes. ${ }^{120-122}$ In some cases, it was shown that the active species was actually PNNP-covered Fe(0) NPs (Scheme 11B). ${ }^{123-124}$ Finally, Fu et al. explored furfural hydrogenation using $\mathrm{Fe}_{2} \mathrm{O}_{3}$ NPs supported on N-doped graphene, with the catalytic activity stemming from the interaction between $\mathrm{Fe}$ and the $\mathrm{N}$ atoms of the support. ${ }^{125}$ 
A)

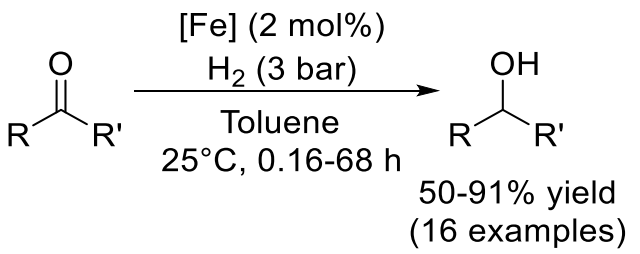

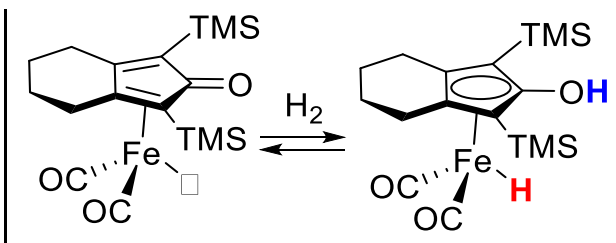

[Fe]: Knölker complex

B)

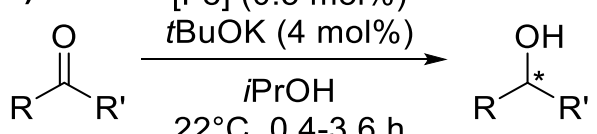

$$
\begin{aligned}
& \text { 86-99\% conversion } \\
& 18-76 \% \text { ee }(S) \\
& \text { (13 examples) }
\end{aligned}
$$

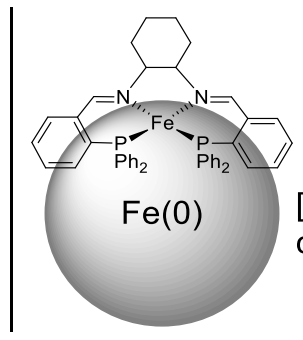

[Fe]: ligandcovered $\mathrm{Fe}(0) \mathrm{NP}$

C)
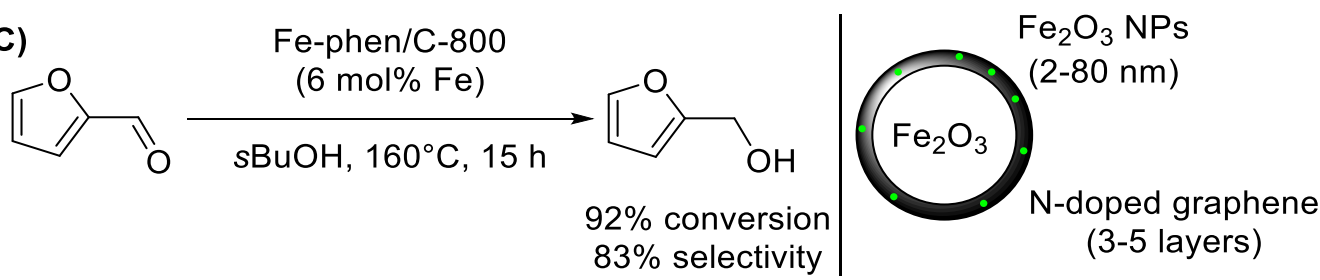

Scheme 11. Ligand and support-assisted Fe-catalyzed hydrogenation: A) Knölker complex B) Morris' PNNP pincer ligand C) $\mathrm{Fe}_{2} \mathrm{O}_{3}$ NPs supported on N-doped graphene

Manganese. Homogeneous Mn has seen tremendous developments in the last two years, since the original breakthrough by Beller and co-workers in 2016. ${ }^{126-129}$ The Mn contamination limit in pharmaceutical compounds is $250 \mathrm{ppm}$ compared to $10 \mathrm{ppm}$ for $\mathrm{Ru}$, added to the fact $\mathrm{Mn}$ is the third most abundant transition metal in the Earth's crust after Fe and Ti. Using an air-stable PNP pincer ligand complex (Scheme 12), they reduced a range of nitriles and carbonyls in high yields (92-99\% yield for carbonyls). ${ }^{130}$ Citral and 5-HMF was successfully reduced at their carbonyl position (78\% and $90 \%$ yield respectively). Yet, the introduction of phosphine moieties within a ligand design greatly increases its cost, superseding the price tag of the metal itself. Since then, phosphine-free ligands have been explored such as NNN pincers, aminopyridine or aminotriazole ligands. ${ }^{131-133}$ These few examples published in only 2 years reveal the scientific excitement around Mn-based complexes, with special relevance to biomass conversion. 


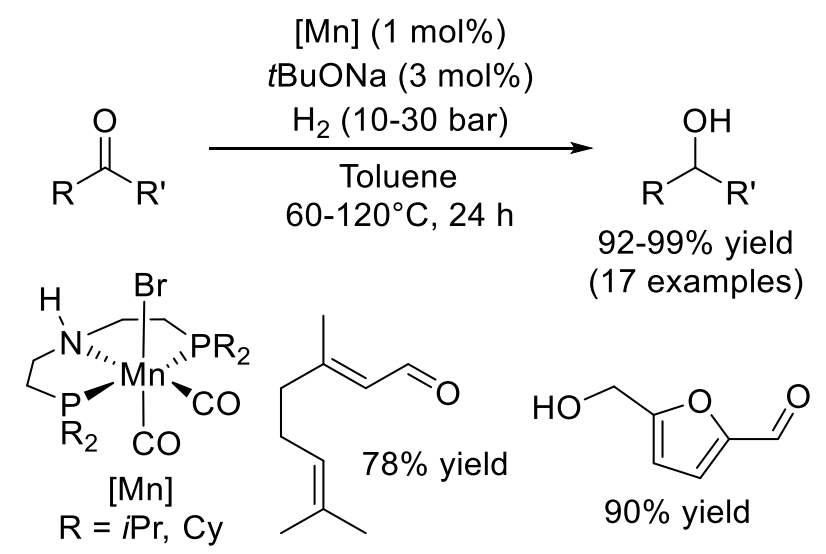

Scheme 12. Mn catalysis for carbonyl hydrogenation.

Nickel. Early mentions of homogeneous $\mathrm{Ni}$ for carbonyl transfer hydrogenation using $i \mathrm{PrOH}$ were performed with halide salts $\left(\mathrm{NiCl}_{2}, \mathrm{NiBr}_{2}\right)$, coupled with $\mathrm{NaOH}$ or $\mathrm{KOH} .{ }^{134-136}$ But contrary to $\mathrm{Fe}$ and $\mathrm{Mn}$, heterogeneous $\mathrm{Ni}$ for carbonyl transfer hydrogenation has then been massively investigated. ${ }^{137}$ For instance $\mathrm{Zr}_{0.8} \mathrm{Ni}_{0.2} \mathrm{O}_{2},{ }^{138}$ Raney Ni, ${ }^{139} \mathrm{Ni} @ \mathrm{CeO}_{2},{ }^{140}$ or Ni(0) NPs generated by the reduction of $\mathrm{NiCl}_{2}$ using metallic $\mathrm{Li}$ all proved competent for carbonyl reduction using $i \mathrm{PrOH} .{ }^{137,141}$ Interestingly, Escande et al. prepared $\mathrm{EcoNi}(0)$ from the thermal decomposition of a Ni-hyperaccumulating plant, Psychotria gabriellae, found in New Caledonia (Scheme 13). ${ }^{142}$ The authors used $\mathrm{Al}_{2} \mathrm{O}_{3}$ as a base and the catalyst was tolerant to $\mathrm{NO}_{2},-\mathrm{CN}$ and $\mathrm{C}=\mathrm{C}$ groups. Typically, citral was fully selectively reduced to citronellol $(97 \%$ yield, $6 \mathrm{~h})$.

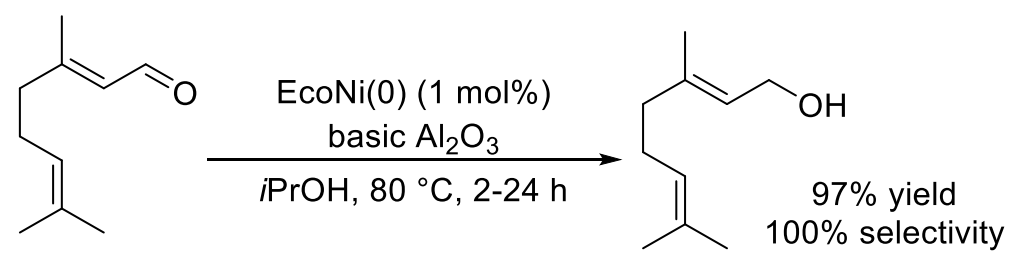

Scheme 13. EcoNi(0)-catalyzed carbonyl transfer hydrogenation.

\section{Magnetic catalysts}

A convenient method to simplify catalyst separation is to use magnetically recoverable NPs (MNPs), either directly as catalysts or as supports for homogeneous or heterogeneous catalysts. ${ }^{143} \mathrm{~A}$ few different strategies exist around this concept: the MNPs can be used directly as catalysts for carbonyl reduction such as magnetic $\mathrm{CuFe}_{2} \mathrm{O}_{4} \mathrm{NPs}$ in conjunction with PMHS as reductant. ${ }^{144}$ Alternatively, magnetic supports such as $\mathrm{Ni}$ on $\mathrm{Fe}_{3} \mathrm{O}_{4}$ NPs can be used to support the catalyst. ${ }^{145}$ Our group, along with Baig et al., has explored this concept with Ru for transfer hydrogenation in $i \mathrm{PrOH}$ (Scheme 14A). ${ }^{53,146}$ In both cases the catalyst was easily 
recyclable up to 4 times. We also immobilized $\mathrm{Ag}$ on $\mathrm{Fe}_{3} \mathrm{O}_{4} \mathrm{NPs}$, made by microwave using carboxymethyl cellulose as a reductant and linker $\left(\mathrm{Ag}-\mathrm{Fe}_{3} \mathrm{O}_{4} @ \mathrm{CMC}\right) .{ }^{147}$ The catalyst was used for the hydrogenation of carbonyls in water, exhibiting full selectivity to $\mathrm{C}=\mathrm{O}$ bonds for citral and $\alpha$-methyl-trans-cinnamaldehyde (Scheme 14B).

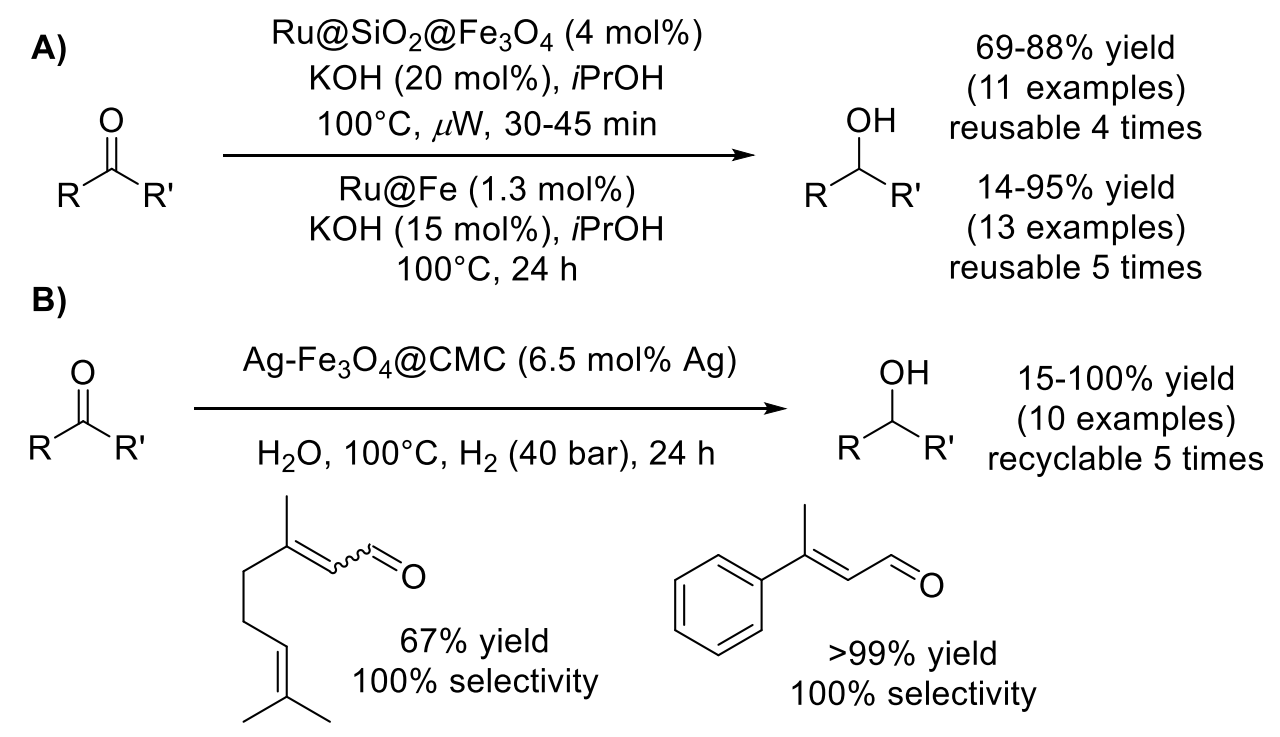

Scheme 14. A) $\mathrm{Ru} @ \mathrm{SiO}_{2} @ \mathrm{Fe}_{3} \mathrm{O}_{4}$ and $\mathrm{Ru} @ \mathrm{Fe}$ for carbonyl transfer hydrogenation B) Ag$\mathrm{Fe}_{3} \mathrm{O}_{4} @ \mathrm{CMC}$-catalyzed hydrogenation of aldehydes in water

\section{Frustrated Lewis Pairs}

Frustrated Lewis Pairs (FLPs) are a combination of Lewis acids and bases, in which sterics are designed to hinder dative bond formation. ${ }^{148-149}$ Stephan and co-workers were first to show that FLP were to be able to split $\mathrm{H}_{2}$, constituting attractive metal-free hydrogenation catalysts. ${ }^{150}$ A major breakthrough in this field was made simultaneously by both the Stephan ${ }^{151-152}$ and the Ashley ${ }^{153-154}$ group, showing that a strong Lewis acid such as $\mathrm{B}\left(\mathrm{C}_{6} \mathrm{~F}_{5}\right)_{3}$ could catalytically reduce carbonyls, in conjunction with $\mathrm{Et}_{2} \mathrm{O}$ or THF as a weak Lewis base (Scheme 15A). ${ }^{155}$ Mummadi et al. adopted the opposite approach from the previous authors, using an aryl-substituted 9-BBN borane as a weak Lewis acid, in conjunction with a strong Lewis base (Scheme 15B). ${ }^{156}$ Their system worked on the gram-scale for EL conversion to GVL (74\% yield). 


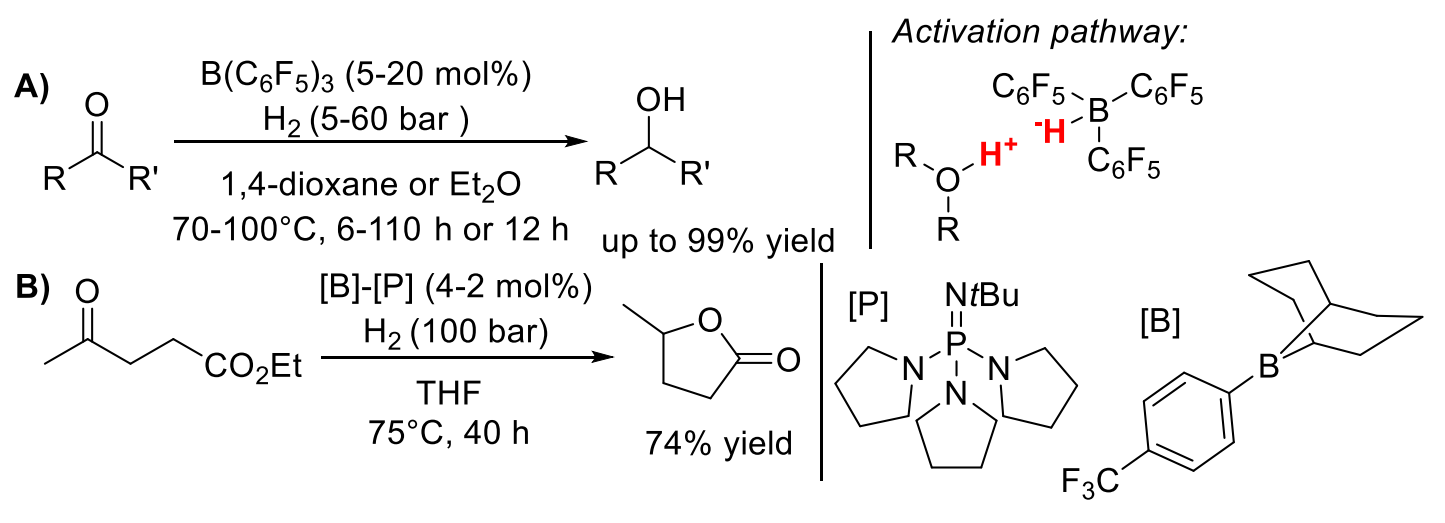

Scheme 15. FLP-catalyzed hydrogenation of carbonyls.

Due to the novelty of FLPs in hydrogenations, no formally heterogenized version has been reported so far. A few closely related systems are worth mentioning though, as they could give some hint on the future of heterogeneous FLPs. Primo et al. reported in 2014 exfoliated graphene as a $\mathrm{C}=\mathrm{C}$ hydrogenation catalyst. ${ }^{157-158}$ While the nature of the active sites remains unclear, the authors did mention the co-existence of basic and acidic sites on their material, effectively exerting a FLP-induced $\mathrm{H}_{2}$ activation.

From the examples covered throughout in this section, the following themes have been tackled:

-Investigation of base metal catalysis. Indeed, base metals such as $\mathrm{Co}, \mathrm{Cu}, \mathrm{Fe}, \mathrm{Ni}$ and $\mathrm{Mn}$ are more abundant than most PGMs but have remained comparatively underdeveloped. ${ }^{48-49,159-160}$ -Improvement of post-reaction catalyst separation and recyclability. This is also possible on homogeneous catalysts, for example by using hydrosoluble complexes, ${ }^{96}$ IL-soluble complexes ${ }^{161}$ or by using magnetically tractable supports. PGM would benefit in particular from a better catalyst re-usability due to their higher cost and toxicity.

-High level of reduction activity and selectivity. In the context of carbonyl reduction, this means that investigation on $\mathrm{C}=\mathrm{O} / \mathrm{C}=\mathrm{C}$ selectivity, low $\mathrm{H}_{2}$ pressure and/or mild reductants should be further pursued. ${ }^{162}$

\section{Hydrogen sources}

Carbonyl hydrogenation illustrate well the importance of metric choice. One of the first green chemistry metrics, concept of atom economy (AE), was developed by Prof. Trost in $1991^{163}$ and it translates the conversion efficiency of a process to integrate every atom of the reactants into the desired product. Unsurprisingly, $\mathrm{H}_{2}$ gas exhibits a full efficiency in terms of atoms employed to reduce a carbonyl, while the atom efficiency of any other reductant falls 
below 11\% (Table 1). However, safety (regarding the use of pressure, or flammability), reactivity, recycling, as well as the sourcing of the reducing agent is not taken into account in AE. ${ }^{164-165}$ Thus transfer hydrogenation is a viable alternative to direct hydrogenation. ${ }^{166}$

\begin{tabular}{|c|c|}
\hline Reductant & \% Active $\mathrm{H}$ \\
\hline $\mathrm{H}_{2}$ & $100 \%$ \\
\hline $\mathrm{NaBH}_{4}$ & $11 \%$ \\
\hline $\mathrm{PMHS}$ & $7 \%$ \\
\hline $\mathrm{HCO}_{2} \mathrm{H}$ & $4 \%$ \\
\hline$i \mathrm{PrOH}$ & $3 \%$ \\
\hline glycerol & $2 \%$ \\
\hline $\mathrm{NaH}_{2} \mathrm{PO}_{2}$ & $2 \%$ \\
\hline glucose & $1 \%$ \\
\hline Hantzsch ester & $0.7 \%$ \\
\hline
\end{tabular}

Table 1. Common reductants in carbonyl reduction-atom economy.

Similarly to what the ACS-GCI did with solvents, they recently published an online reagent guide, comparing for a given process several reagents with considerations on their environmental impact and scalability. ${ }^{86}$ Furthermore, the field of transfer hydrogenation will greatly benefit from future progresses in hydrogen storage, as reviewed by Sordakis et al. ${ }^{167}$

The most popular hydrogen sources in the pharmaceutical industry, shown by their prevalence in large scale processes, are hydride salts $\left(\mathrm{NaBH}_{4}, \mathrm{LiAlH}_{4}\right)$. These are obtained from respectively the treatment of $\mathrm{B}(\mathrm{OMe})_{3}$ with $\mathrm{NaH}$ (discovered in $1953^{168}$ ) and $\mathrm{AlCl}_{3}$ with $\mathrm{LiH}$ (discovered in $1947^{169}$ ). Hydride salts must be used in stoichiometric amounts, despite efforts made to use them in catalytic amounts, ${ }^{170}$ and they mostly suffer from flammability and cumbersome waste generation. Alcoholic hydrogen sources are available from biomass (EtOH, $\mathrm{MeOH}$ ) and their byproduct can be potentially recycled (Scheme 16). ${ }^{164}$ Moreover, some waste chemicals from the biodiesel and silicon industry can be re-used as reductants (respectively glycerol and PMHS), opening up new avenues in sustainable transfer hydrogenation. Other unusual reductants such as glucose ${ }^{171}$ or $\mathrm{NaH}_{2} \mathrm{PO}_{2}{ }^{172}$ have been explored as well for carbonyl reduction. 


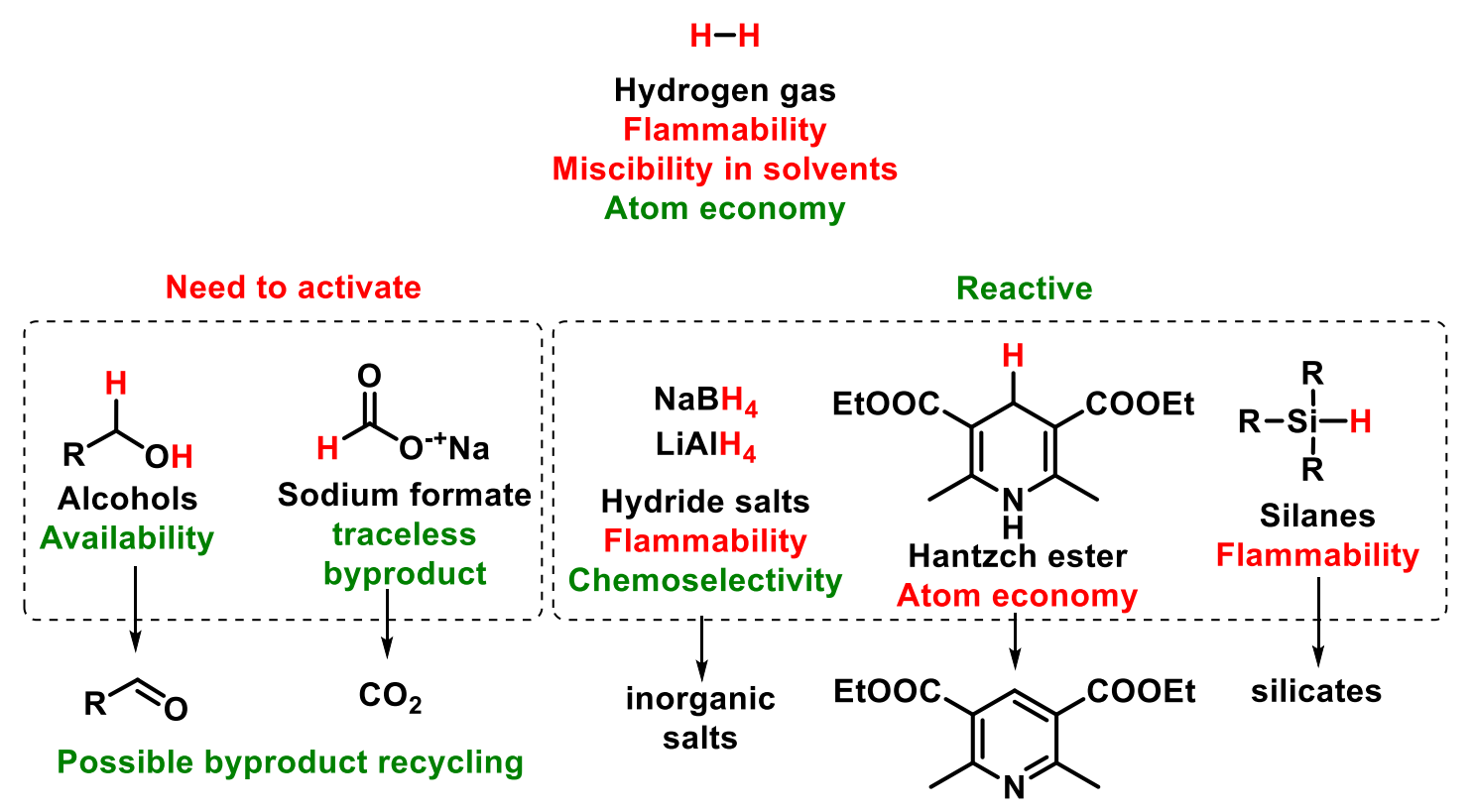

Scheme 16. An overview of hydrogenation sources.

\section{Short chain alcohols}

The discovery of hydride salts as reductants allowed in their time supplanting the 'classical' reduction methods such as the Meerwein-Ponndorf-Verley (MPV) reduction, discovered in the 1920s. ${ }^{173-176}$ In this process, the carbonyl is introduced to an excess of reducing alcohol $(i \mathrm{PrOH})$, with an $\mathrm{Al}$ or $\mathrm{B}$-based transfer agent such as $\mathrm{Al}(\mathrm{O} i \mathrm{Pr})_{3}$. Upon coordination of an alkoxide to $\mathrm{Al}^{3+}$ or $\mathrm{B}^{3+}$, its $\alpha$-hydride can be readily transferred to the carbonyl through a 6-member transition state (Scheme 17A). Since the process is reversible, an excess of $i \mathrm{PrOH}$ and $\mathrm{Al}(\mathrm{O} i \mathrm{Pr})_{3}$ is required to drive the reaction to completion, as well as typically long reflux times $(3-8 \mathrm{~h}) .{ }^{177}$ However, the prospect of using alcohols as safe reducing agents sparked interest into improving over the original MPV reaction, that remained an inspiring system. For instance, it has been discovered that adding trifluoroacetic acid or using sterically hindered Al/B complexes helped drastically cutting reaction down time (up to 15 min). ${ }^{177-181}$ The MPV reaction has seen in the last 5 years much development on GVL production, based on $\mathrm{Al}^{182-183}$ and $\mathrm{Zr}^{184-188}$ oxides as catalysts for LA and derivatives reduction (Scheme 17B). ${ }^{189}$ Lately, a more recent variant of MPV reactions was discovered by using cheap and widely available metal alkali such as $\mathrm{NaOH}$ or $\mathrm{KOH} .{ }^{190-191}$ Similarly to $\mathrm{Al}^{3+}$ and $\mathrm{B}^{3+}, \mathrm{K}^{+}$and $\mathrm{Na}^{+}$cations are also able to mediate the direct hydride transfer through a similar 6-member intermediate (Scheme 17C). 
A)

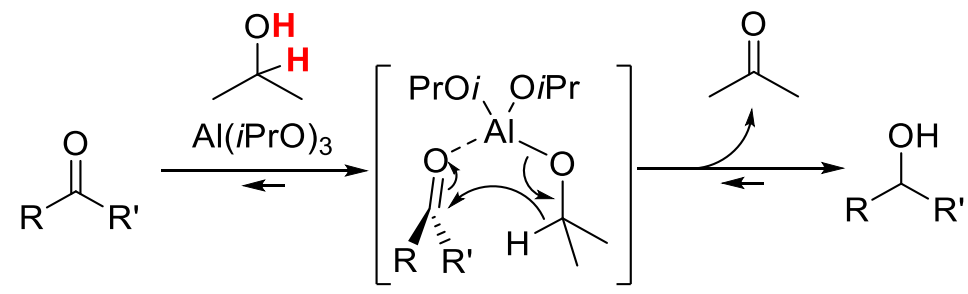

B)

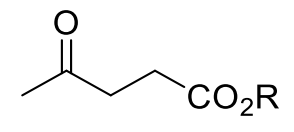

$$
\mathrm{Al}^{\mathrm{III}}, \mathrm{Sn}^{\mathrm{IV}}, \mathrm{Zr}^{\mathrm{IV}} \text { cat. }
$$

$\mathrm{R}=\mathrm{H}, \mathrm{Et}, n \mathrm{Bu}$

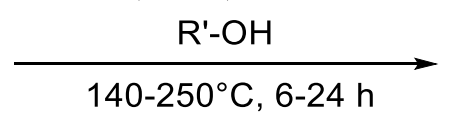

$\mathrm{R}^{\prime}=\mathrm{H}, \mathrm{Et}, \mathrm{Pr}, \mathrm{Bu}$<smiles>CC1CCC(=O)O1</smiles>

GVL

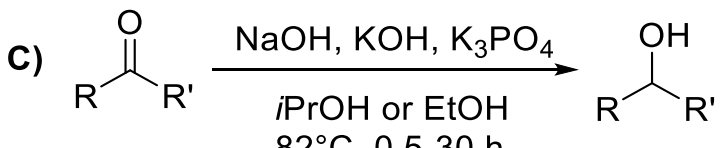

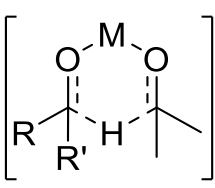

MPV-style activation of $\mathrm{PrOH}$ using M-B

Scheme 17. MPV reduction: A) Mechanism B) LA reduction C) Base-catalyzed version.

\section{Formate}

Formic acid $\left(\mathrm{HCO}_{2} \mathrm{H}, \mathrm{FA}\right)$ is the simplest of carboxylic acids, made from the carbonylation of $\mathrm{MeOH}$ into $\mathrm{HCO}_{2} \mathrm{Me}$, and subsequent hydrolysis. ${ }^{192}$ The direct synthesis of formic acid from $\mathrm{CO}_{2}$ reduction with $\mathrm{H}_{2}$ or water by photoelectrocatalysis is a very active research topic. ${ }^{193}$ In conjunction with a base ( $\operatorname{such}$ as $\mathrm{Et}_{3} \mathrm{~N}$ ) or as sodium formate, formic acid has been widely used as a reducing agent, decomposing into $\mathrm{CO}_{2}$ and $\mathrm{H}_{2}$ under catalytic conditions. ${ }^{194}$ It has been particularly useful in prochiral ketone reduction into secondary alcohol, using Ir, ${ }^{195} \mathrm{Ru},{ }^{196-198} \mathrm{Rh}$ complexes, ${ }^{199}$ or enzymes ${ }^{200}$ (Scheme 18A). Furthermore, LA is co-generated with LA 5 -HMF acidolysis, ${ }^{17}$ giving a strong incentive to use FA to reduce LA. ${ }^{4}$ A seminal example was reported by Du et al., using small Au NPs supported on $\mathrm{ZrO}_{2}$ $\left(\mathrm{Au} @ \mathrm{ZrO}_{2}\right){ }^{201}$ The catalyst was tested on freshly prepared solutions of LA/FA mixture made from the treatment of carbohydrates with $\mathrm{H}_{2} \mathrm{SO}_{4}$, establishing the robustness of their method. The $\mathrm{Fu}$ group also showed the viability of homogeneous Fe/Tris[(2diphenylphosphino)ethyl]phosphine complexes for LA reduction. ${ }^{202}$ Finally, Varkolu et al. used $\mathrm{Ni}$ supported on $\mathrm{SiO}_{2}\left(\mathrm{Ni} @ \mathrm{SiO}_{2}\right)$ and applied in continuous flow for GVL synthesis (Scheme 18B). ${ }^{203}$ 
B)<smiles>O=C(O)CCC(=O)CCC(=O)c1ccc(F)o1</smiles>

$\mathrm{Fe}\left(\mathrm{CF}_{3} \mathrm{SO}_{2}\right)_{2} / \mathrm{L} 1$

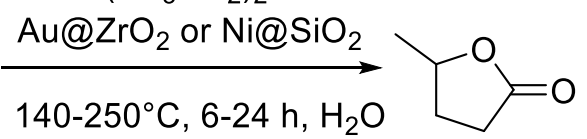

GVL

Scheme 18. Formic acid/akali metal formate in A) prochiral reduction and B) Co-generation of LA and FA from 5-HMF and subsequent reduction to GVL.

\section{Glycerol}

Glycerol is a non-toxic, non-hazardous, and non-volatile liquid, the 1,3-dihydroxylated analogue of $i \mathrm{PrOH} .{ }^{204}$ Contrary to $i \mathrm{PrOH}$ though, glycerol is a biomass waste from manufacture of biodiesel fuel from vegetable oils $(100 \mathrm{~kg}$ generated per ton of biodiesel fuel produced, Scheme 19A). ${ }^{205}$ Thanks to its low price, there has been a strong economic incentive to use it as a solvent and a reducing agent. In catalytic carbonyl reduction, homogeneous $\mathrm{Ru}$ and $\mathrm{Ir}$

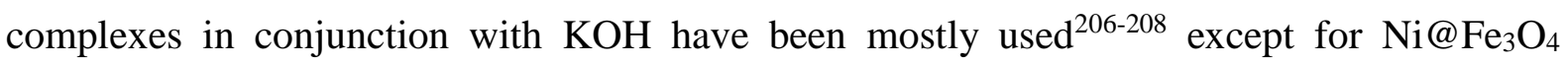
reported by Gawande et al. (Scheme 19B). ${ }^{209}$

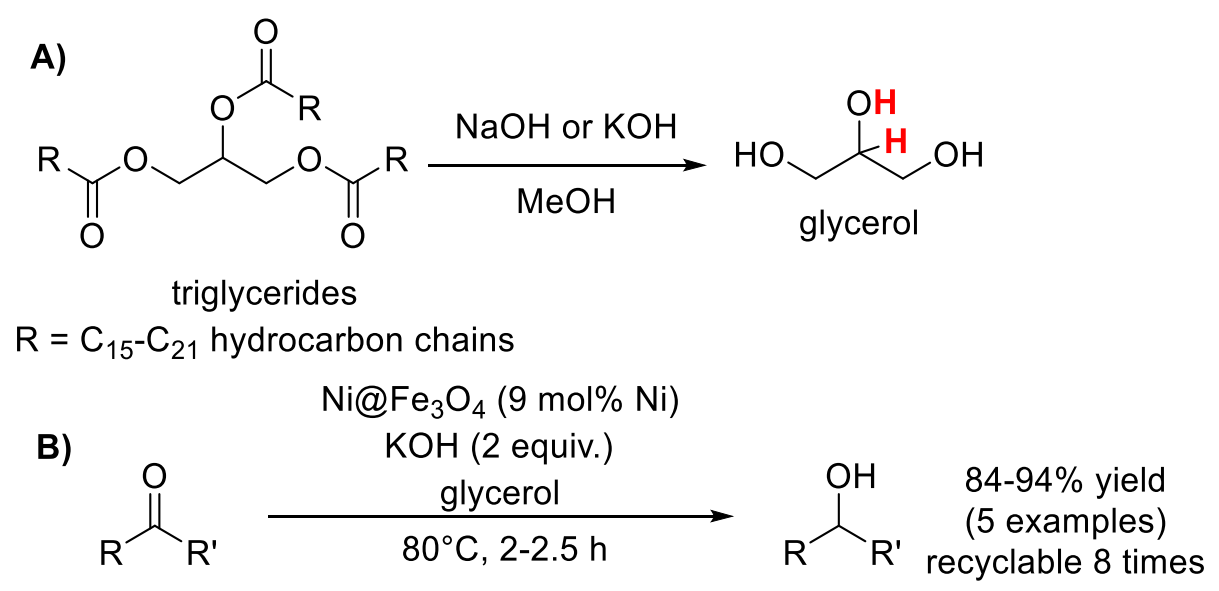

Scheme 19. A) Glycerol production from biomass B) $\mathrm{Ni} @ \mathrm{Fe}_{3} \mathrm{O}_{4}$ for carbonyl reduction in glycerol.

\section{PMHS}

In contrast to most silanes, PMHS is an inexpensive and non-toxic reducing agent. In the absence of an activator, it is an inert and easy to handle liquid. It was first prepared by Sauer and co-workers, ${ }^{210}$ and has been since reported in a substantial number of reduction 
processes. ${ }^{211}$ Upon treatment with $\mathrm{BF}_{3} \cdot \mathrm{OEt}_{2}$, the resulting PDMS byproduct can be recycled into $\mathrm{MeSiH}_{3-\mathrm{x}} \mathrm{F}_{\mathrm{x}}$ synthons that are useful building blocks in the silicon industry. ${ }^{212}$ Early reports consisted in using Sn salts as activators, ${ }^{213-215}$ and since then a wider variety of activators, especially in metal-free schemes, has been reported. Nucleophilic activators such as fluorides, ${ }^{216}$ phosphines $^{217}$ or bases ${ }^{218}$ have been successfully applied to PMHS-mediated ketone hydrosilylation (Scheme 20). Eventually, non-noble metals such as $\mathrm{Fe}^{219-221}$ and $\mathrm{Zn}$ were shown to activate PMHS as well, with $\mathrm{Zn}$ being able to enantioselective prochiral ketones into chiral secondary alcohols. ${ }^{222-225}$

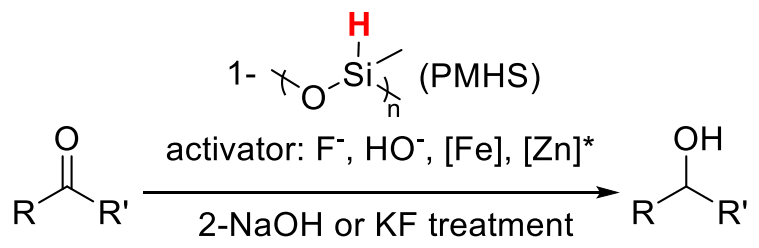

Scheme 20. PMHS for carbonyl reduction.

\section{Conclusion}

As seen throughout the plethora of examples of carbonyl reduction exposed here, a broad and diverse toolbox of chemical methods is available to organic chemists in order to design a performant reduction process in the context of biomass upgrading. We have attempted here to illustrate efforts to introduce various green chemistry concepts including the choice of substrate, energy, solvent, catalyst and reducing agent. Our hope is to show, educate, and ease the application of sustainability methods to the chemists to come. These examples showcase an interesting trend in the field. While the use of water, or mechanochemistry are very hot topics and are certainly innovative, they both rely in much older concepts. Water has always been the solvent of choice in biochemical pathways, and on Earth's lifetime scale the use of organic solvents in modern organic chemistry can be seen as an historical anomaly. Likewise, mechanochemistry has been used in human history long before the first oil bath was ever used, ${ }^{226}$ and photochemistry or iron catalysis has been fully exploited by nature for even longer, as plants and blood cells can testify. These re-discovered techniques are key to tackle longstanding challenges. In fact, some fundamental chemical considerations such as solvent effect, substrate solubility or reaction chemoselectivity are worth considering through these new scopes. ${ }^{40}$

\section{Authors biography}




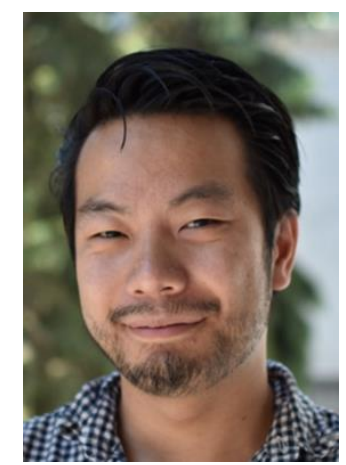

Alain Li received his MSc. in organic chemistry from l'Ecole Nationale Supérieure de Chimie of Montpellier, France in 2013. He then obtained his PhD in 2019 from McGill university in Montréal, Canada, working under the co-supervision of Prof. Audrey Moores and Prof. ChaoJun Li on sustainable catalysis applied to carbonyl reduction.

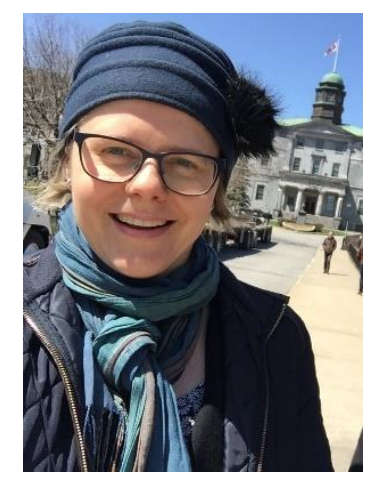

Audrey Moores received her BSc (2001), MSc (2002) and PhD (2005) from Ecole Polytechnique, Palaiseau in France. She did a post-doctoral fellowship at Yale University, before starting her independent carrier at McGill University, Montréal, Canada as a Canada Research Chair in Green Chemistry in 2007. She became an Associate Professor in 2014. Between 2012 and 2016 she was the co-associate director of the Center for Green Chemistry and Catalysis. Since 2017, she co-leads the McGill Sustainability Systems Initiative-Materials. Her research focuses on catalysis and photocatalysis using metal, metal oxide and biomassbased nanomaterials, with a special emphasis on sustainable processes and use of earth abundant starting materials. She also develops solid phase methods to access nanomaterials and functional polymers. She was selected as an emerging leader in 2017 by the RSC journal Green Chemistry

\section{References}

1. Anastas, P. T.; Kirchhoff, M. M.; Williamson, T. C., Catalysis as a foundational pillar of green chemistry. Appl. Catal., A 2001, 221 (1), 3-13. 
2. Anastas, P. T.; Warner, J. C., Green chemistry : theory and practice. Oxford University Press: Oxford ;, 2000.

3. Vries, J. G. d.; Elsevier, C. J., The Handbook of Homogeneous Hydrogenation. 2008.

4. Gilkey, M. J.; Xu, B., Heterogeneous Catalytic Transfer Hydrogenation as an Effective Pathway in Biomass Upgrading. ACS Catal. 2016, 6 (3), 1420-1436.

5. $\quad$ Rinaldi, R., Catalytic Hydrogenation for Biomass Valorization. 2014.

6. Wilde, M. v., Vermischte Mittheilungen. Chem. Ber. 1874, 7 (1), 352-357.

7. Sanfilippo, D.; Rylander, P. N., Hydrogenation and Dehydrogenation. In Ullmann's Encyclopedia of Industrial Chemistry, Wiley-WCH, Ed. 2009.

8. Burkhardt, E. R.; Matos, K., Boron Reagents in Process Chemistry: Excellent Tools for Selective Reductions. Chem. Rev. 2006, 106 (7), 2617-2650.

9. Hedberg, C., Carbonyl Hydrogenation. In Modern Reduction Methods, Wiley-WCH, Ed. 2008.

10. Bernardis, F. L.; Grant, R. A.; Sherrington, D. C., A review of methods of separation of the platinum-group metals through their chloro-complexes. React. Funct. Polym. 2005, 65 (3), 205-217.

11. Ravindra, K.; Bencs, L.; Van Grieken, R., Platinum group elements in the environment and their health risk. Sci. Total Environ. 2004, 318 (1), 1-43.

12. Jantan, K. A.; Kwok, C. Y.; Chan, K. W.; Marchiò, L.; White, A. J. P.; Deplano, P.; Serpe, A.; Wilton-Ely, J. D. E. T., From recovered metal waste to high-performance palladium catalysts. Green Chem. 2017, 19 (24), 5846-5853.

13. Besson, M.; Gallezot, P.; Pinel, C., Conversion of Biomass into Chemicals over Metal Catalysts. Chem. Rev. 2014, 114 (3), 1827-1870.

14. Allen, D. T.; Hwang, B. J.; Licence, P.; Pradeep, T.; Subramaniam, B., Advancing the Use of Sustainability Metrics. ACS Sustainable Chem. Eng. 2015, 3 (10), 2359-2360.

15. Alonso, D. M.; Bond, J. Q.; Dumesic, J. A., Catalytic conversion of biomass to biofuels. Green Chem. 2010, 12 (9), 1493-1513.

16. Kamm, B., Production of Platform Chemicals and Synthesis Gas from Biomass. Angew. Chem. Int. Ed. 2007, 46 (27), 5056-5058.

17. Pileidis, F.; Titirici, M.-M., Levulinic Acid Biorefineries: New Challenges for Efficient Utilization of Biomass. ChemSusChem 2016, 9 (6), 562-582.

18. Gallezot, P.; Richard, D., Selective Hydrogenation of $\alpha, \beta$-Unsaturated Aldehydes. Catal. Rev. 1998, 40 (1-2), 81-126.

19. Anastas, P. T.; Lankey, R. L., Life cycle assessment and green chemistry: the yin and yang of industrial ecology. Green Chem. 2000, 2 (6), 289-295.

20. Montazeri, M.; Eckelman, M. J., Life Cycle Assessment of Catechols from Lignin Depolymerization. ACS Sustainable Chem. Eng. 2016, 4 (3), 708-718.

21. Tufvesson, L. M.; Tufvesson, P.; Woodley, J. M.; Börjesson, P., Life cycle assessment in green chemistry: overview of key parameters and methodological concerns. The International Journal of Life Cycle Assessment 2013, 18 (2), 431-444.

22. Jacquemin, L.; Pontalier, P.-Y.; Sablayrolles, C., Life cycle assessment (LCA) applied to the process industry: a review. The International Journal of Life Cycle Assessment 2012, 17 (8), 1028-1041.

23. Bozell, J. J.; Moens, L.; Elliott, D. C.; Wang, Y.; Neuenscwander, G. G.; Fitzpatrick, S. W.; Bilski, R. J.; Jarnefeld, J. L., Production of levulinic acid and use as a platform chemical for derived products. Resour. Conserv. Recycl. 2000, 28 (3), 227-239.

24. Horváth, I. T.; Mehdi, H.; Fábos, V.; Boda, L.; Mika, L. T., $\gamma$-Valerolactone-a sustainable liquid for energy and carbon-based chemicals. Green Chem. 2008, 10 (2), 238-242. 
25. Manzer, L. E., Catalytic synthesis of $\alpha$-methylene- $\gamma$-valerolactone: a biomass-derived acrylic monomer. Appl. Catal., A 2004, 272 (1), 249-256.

26. Bond, J. Q.; Wang, D.; Alonso, D. M.; Dumesic, J. A., Interconversion between $\gamma$ valerolactone and pentenoic acid combined with decarboxylation to form butene over silica/alumina. J. Catal. 2011, 281 (2), 290-299.

27. Serrano-Ruiz, J. C.; Wang, D.; Dumesic, J. A., Catalytic upgrading of levulinic acid to 5-nonanone. Green Chem. 2010, 12 (4), 574-577.

28. Touchy, A. S.; Hakim Siddiki, S. M. A.; Kon, K.; Shimizu, K.-i., Heterogeneous Pt Catalysts for Reductive Amination of Levulinic Acid to Pyrrolidones. ACS Catal. 2014, 4 (9), 3045-3050.

29. Cai, B.; Zhou, X.-C.; Miao, Y.-C.; Luo, J.-Y.; Pan, H.; Huang, Y.-B., Enhanced Catalytic Transfer Hydrogenation of Ethyl Levulinate to $\gamma$-Valerolactone over a Robust $\mathrm{Cu}-\mathrm{Ni}$ Bimetallic Catalyst. ACS Sustainable Chem. Eng. 2017, 5 (2), 1322-1331.

30. Chheda, J. N.; Román-Leshkov, Y.; Dumesic, J. A., Production of 5hydroxymethylfurfural and furfural by dehydration of biomass-derived mono- and polysaccharides. Green Chem. 2007, 9 (4), 342-350.

31. Bicker, M.; Hirth, J.; Vogel, H., Dehydration of fructose to 5-hydroxymethylfurfural in sub- and supercritical acetone. Green Chem. 2003, 5 (2), 280-284.

32. Hu, L.; Xu, J.; Zhou, S.; He, A.; Tang, X.; Lin, L.; Xu, J.; Zhao, Y., Catalytic Advances in the Production and Application of Biomass-Derived 2,5-Dihydroxymethylfuran. ACS Catal. 2018, 8 (4), 2959-2980.

33. Zeng, C.; Seino, H.; Ren, J.; Hatanaka, K.; Yoshie, N., Bio-Based Furan Polymers with Self-Healing Ability. Macromolecules 2013, 46 (5), 1794-1802.

34. Sacia, E. R.; Balakrishnan, M.; Bell, A. T., Biomass conversion to diesel via the etherification of furanyl alcohols catalyzed by Amberlyst-15. J. Catal. 2014, 313, 70-79.

35. Harris, J. M.; Keranen, M. D.; O'Doherty, G. A., Syntheses of d- and 1-Mannose, Gulose, and Talose via Diastereoselective and Enantioselective Dihydroxylation Reactions. $J$. Org. Chem. 1999, 64 (9), 2982-2983.

36. Yan, K.; Wu, G.; Lafleur, T.; Jarvis, C., Production, properties and catalytic hydrogenation of furfural to fuel additives and value-added chemicals. Renew. Sust. Ener. Rev. 2014, 38, 663-676.

37. Hronec, M.; Fulajtárova, K.; Mičušik, M., Influence of furanic polymers on selectivity of furfural rearrangement to cyclopentanone. Appl. Catal., A 2013, 468, 426-431.

38. Trasarti, A. F.; Marchi, A. J.; Apesteguía, C. R., Highly selective synthesis of menthols from citral in a one-step process. J. Catal. 2004, 224 (2), 484-488.

39. Stolle, A.; Gallert, T.; Schmoger, C.; Ondruschka, B., Hydrogenation of citral: a widespread model reaction for selective reduction of $\alpha, \beta$-unsaturated aldehydes. $R S C A d v$. 2013, 3 (7), 2112-2153.

40. Mäki-Arvela, P.; Hájek, J.; Salmi, T.; Murzin, D. Y., Chemoselective hydrogenation of carbonyl compounds over heterogeneous catalysts. Appl. Catal., A 2005, 292, 1-49.

41. Gawande, M. B.; Shelke, S. N.; Zboril, R.; Varma, R. S., Microwave-Assisted Chemistry: Synthetic Applications for Rapid Assembly of Nanomaterials and Organics. Acc. Chem. Res. 2014, 47 (4), 1338-1348.

42. Oliver Kappe, C., Microwave dielectric heating in synthetic organic chemistry. Chem. Soc. Rev. 2008, 37 (6), 1127-1139.

43. Kappe, C. O., Controlled Microwave Heating in Modern Organic Synthesis. Angew. Chem. Int. Ed. 2004, 43 (46), 6250-6284.

44. Oliver Kappe, C., Microwave Theory. In Practical Microwave Synthesis for Organic Chemists, Books, W. O., Ed. 2009. 
45. Bogdał, D.; Prociak, A., Fundamentals of Microwaves. In Microwave-Enhanced Polymer Chemistry and Technology, 2007.

46. Razzaq, T.; Kappe, C. O., On the Energy Efficiency of Microwave-Assisted Organic Reactions. ChemSusChem 2008, 1 (1-2), 123-132.

47. Priecel, P.; Lopez-Sanchez, J. A., Advantages and Limitations of Microwave Reactors: From Chemical Synthesis to the Catalytic Valorization of Biobased Chemicals. ACS Sustainable Chem. Eng. 2019, 7 (1), 3-21.

48. Li, Y.-Y.; Yu, S.-L.; Shen, W.-Y.; Gao, J.-X., Iron-, Cobalt-, and Nickel-Catalyzed Asymmetric Transfer Hydrogenation and Asymmetric Hydrogenation of Ketones. Acc. Chem. Res. 2015, 48 (9), 2587-2598.

49. Wang, D.; Astruc, D., The recent development of efficient Earth-abundant transitionmetal nanocatalysts. Chem. Soc. Rev. 2017, 46 (3), 816-854.

50. Barbry, D.; Torchy, S., Accelerated Reduction of Carbonyl Compounds under Microwave Irradiation. Tetrahedron Lett. 1997, 38 (17), 2959-2960.

51. Kazemi, F.; Kiasat, A. R., Reduction of carbonyl compounds to the corresponding alcohols with isopropanol on dehydrated alumina under microwave irradiation. Synth. Comm. 2002, 32 (14), 2255-2260.

52. Polshettiwar, V.; Baruwati, B.; Varma, R. S., Nanoparticle-supported and magnetically recoverable nickel catalyst: a robust and economic hydrogenation and transfer hydrogenation protocol. Green Chem. 2009, 11 (1), 127-131.

53. Nasir Baig, R. B.; Varma, R. S., Magnetic Silica-Supported Ruthenium Nanoparticles: An Efficient Catalyst for Transfer Hydrogenation of Carbonyl Compounds. ACS Sustainable Chem. Eng. 2013, 1 (7), 805-809.

54. Yoshida, K.; Gonzalez-Arellano, C.; Luque, R.; Gai, P. L., Efficient hydrogenation of carbonyl compounds using low-loaded supported copper nanoparticles under microwave irradiation. Appl. Catal., A 2010, 379 (1), 38-44.

55. Gowda, R.; Chen, E., Recyclable Earth-Abundant Metal Nanoparticle Catalysts for Selective Transfer Hydrogenation of Levulinic Acid to Produce $\gamma$-Valerolactone. ChemSusChem 2016, 9 (2), 181-185.

56. Clark, J.; Farmer, T.; Hunt, A.; Sherwood, J., Opportunities for Bio-Based Solvents Created as Petrochemical and Fuel Products Transition towards Renewable Resources. Int. J. Mol. Sci. 2015, 16 (8), 17101.

57. Clarke, C. J.; Tu, W.-C.; Levers, O.; Bröhl, A.; Hallett, J. P., Green and Sustainable Solvents in Chemical Processes. Chem. Rev. 2018, 118 (2), 747-800.

58. Do, J.-L.; Friščić, T., Mechanochemistry: A Force of Synthesis. ACS Cent. Sci. 2017, $3(1), 13-19$.

59. Fumio, T.; Koji, K.; Minoru, Y., NaBH4 Reduction of Ketones in the Solid State. Angew. Chem. Int. Ed. 1989, 28 (3), 320-321.

60. Cho, B. T.; Kang, S. K.; Kim, M. S.; Ryu, S. R.; An, D. K., Solvent-free reduction of aldehydes and ketones using solid acid-activated sodium borohydride. Tetrahedron 2006, 62 (34), 8164-8168.

61. Mack, J.; Fulmer, D.; Stofel, S.; Santos, N., The first solvent-free method for the reduction of esters. Green Chem. 2007, 9 (10), 1041-1043.

62. Reza, N.-J. M.; Javad, M.; G., D. M.; Gerd, K., Sodium Tetraalkoxyborates: Intermediates for the Quantitative Reduction of Aldehydes and Ketones to Alcohols through Ball Milling with NaBH4. Eur. J. Org. Chem. 2009, 2009 (21), 3567-3572.

63. Solà, R.; Sutcliffe, O. B.; Banks, C. E.; Maciá, B., Ball mill and microwave assisted synthetic routes to Fluoxetine. Sust. Chem. Pharma. 2017, 5, 14-21. 
64. Li, A. Y.; Segalla, A.; Li, C.-J.; Moores, A., Mechanochemical Metal-Free Transfer Hydrogenation of Carbonyls Using Polymethylhydrosiloxane as the Hydrogen Source. ACS Sustainable Chem. Eng. 2017, 5 (12), 11752-11760.

65. Liu, X.; Sun, D.; Yuan, R.; Fu, X.; Li, Z., Efficient visible-light-induced hydrogenation over composites of CdS and ruthenium carbonyl complexes. J. Catal. 2013, 304, 1-6.

66. Joyce-Pruden, C.; Pross, J. K.; Li, Y., Photoinduced reduction of aldehydes on titanium dioxide. J. Org. Chem. 1992, 57 (19), 5087-5091.

67. Kohtani, S.; Yoshioka, E.; Saito, K.; Kudo, A.; Miyabe, H., Photocatalytic hydrogenation of acetophenone derivatives and diaryl ketones on polycrystalline titanium dioxide. Catal. Commun. 2010, 11 (13), 1049-1053.

68. Zhang, M.; Rouch, W. D.; McCulla, R. D., Conjugated Polymers as Photoredox Catalysts: Visible-Light-Driven Reduction of Aryl Aldehydes by Poly(p-phenylene). Eur. J. Org. Chem. 2012, 2012 (31), 6187-6196.

69. Sharma, P.; Sasson, Y., A photoactive catalyst Ru-g-C3N4 for hydrogen transfer reaction of aldehydes and ketones. Green Chem. 2017, 19 (3), 844-852.

70. Ghosh, T.; Slanina, T.; König, B., Visible light photocatalytic reduction of aldehydes by $\mathrm{Rh}$ (iii)-H: a detailed mechanistic study. Chem. Sci. 2015, 6 (3), 2027-2034.

71. Call, A.; Casadevall, C.; Acuña-Parés, F.; Casitas, A.; Lloret-Fillol, J., Dual cobaltcopper light-driven catalytic reduction of aldehydes and aromatic ketones in aqueous media. Chem. Sci. 2017, 8 (7), 4739-4749.

72. Zeng, S.; Kar, P.; Thakur, U. K.; Shankar, K., A review on photocatalytic CO2 reduction using perovskite oxide nanomaterials. Nanotechnology 2018, 29 (5), 052001.

73. Wang, W.-H.; Himeda, Y.; Muckerman, J. T.; Manbeck, G. F.; Fujita, E., CO2 Hydrogenation to Formate and Methanol as an Alternative to Photo- and Electrochemical CO2 Reduction. Chem. Rev. 2015, 115 (23), 12936-12973.

74. Halas, N. J.; Lal, S.; Chang, W.-S.; Link, S.; Nordlander, P., Plasmons in Strongly Coupled Metallic Nanostructures. Chem. Rev. 2011, 111 (6), 3913-3961.

75. Hao, C.-H.; Guo, X.-N.; Pan, Y.-T.; Chen, S.; Jiao, Z.-F.; Yang, H.; Guo, X.-Y., Visible-Light-Driven Selective Photocatalytic Hydrogenation of Cinnamaldehyde over Au/SiC Catalysts. J. Am. Chem. Soc. 2016, 138 (30), 9361-9364.

76. Landry, M. J.; Gellé, A.; Meng, B. Y.; Barrett, C. J.; Moores, A., Surface-PlasmonMediated Hydrogenation of Carbonyls Catalyzed by Silver Nanocubes under Visible Light. ACS Catal. 2017, 7 (9), 6128-6133.

77. Gu, Y.; Jérôme, F., Bio-based solvents: an emerging generation of fluids for the design of eco-efficient processes in catalysis and organic chemistry. Chem. Soc. Rev. 2013, 42 (24), 9550-9570.

78. Jessop, P. G., Searching for green solvents. Green Chem. 2011, 13 (6), 1391-1398.

79. Zhu, S.; Wu, Y.; Chen, Q.; Yu, Z.; Wang, C.; Jin, S.; Ding, Y.; Wu, G., Dissolution of cellulose with ionic liquids and its application: a mini-review. Green Chem. 2006, 8 (4), 325327.

80. Olivier-Bourbigou, H.; Magna, L., Ionic liquids: perspectives for organic and catalytic reactions. J. Mol. Catal. A: Chem. 2002, 182-183, 419-437.

81. Anderson, K.; Goodrich, P.; Hardacre, C.; Rooney, D. W., Heterogeneously catalysed selective hydrogenation reactions in ionic liquids. Green Chem. 2003, 5 (4), 448-453.

82. Alfonsi, K.; Colberg, J.; Dunn, P. J.; Fevig, T.; Jennings, S.; Johnson, T. A.; Kleine, H. P.; Knight, C.; Nagy, M. A.; Perry, D. A.; Stefaniak, M., Green chemistry tools to influence a medicinal chemistry and research chemistry based organisation. Green Chem. 2008, 10 (1), 3136. 
83. Henderson, R. K.; Jiménez-González, C.; Constable, D. J. C.; Alston, S. R.; Inglis, G. G. A.; Fisher, G.; Sherwood, J.; Binks, S. P.; Curzons, A. D., Expanding GSK's solvent selection guide - embedding sustainability into solvent selection starting at medicinal chemistry. Green Chem. 2011, 13 (4), 854-862.

84. Alder, C. M.; Hayler, J. D.; Henderson, R. K.; Redman, A. M.; Shukla, L.; Shuster, L. E.; Sneddon, H. F., Updating and further expanding GSK's solvent sustainability guide. Green Chem. 2016, 18 (13), 3879-3890.

85. Prat, D.; Pardigon, O.; Flemming, H.-W.; Letestu, S.; Ducandas, V.; Isnard, P.; Guntrum, E.; Senac, T.; Ruisseau, S.; Cruciani, P.; Hosek, P., Sanofi's Solvent Selection Guide: A Step Toward More Sustainable Processes. Org. Proc. Res. Dev. 2013, 17 (12), $1517-$ 1525.

86. Roundtable, A. G. C. I. P. Solvent Selection Guide: Version 2.0. https://www.acs.org/content/dam/acsorg/greenchemistry/industriainnovation/roundtable/acsgci-pr-solvent-selection-guide.pdf (accessed 21/01/2019).

87. Rideout, D. C.; Breslow, R., Hydrophobic acceleration of Diels-Alder reactions. J. Am. Chem. Soc. 1980, 102 (26), 7816-7817.

88. Du, Q.; Freysz, E.; Shen, Y. R., Surface Vibrational Spectroscopic Studies of Hydrogen Bonding and Hydrophobicity. Science 1994, 264 (5160), 826-828.

89. Jung, Y.; Marcus, R. A., On the Theory of Organic Catalysis "on Water". J. Am. Chem. Soc. 2007, 129 (17), 5492-5502.

90. La Sorella, G.; Strukul, G.; Scarso, A., Recent advances in catalysis in micellar media. Green Chem. 2015, 17 (2), 644-683.

91. Lipshutz, B. H.; Isley, N. A.; Fennewald, J. C.; Slack, E. D., On the Way Towards Greener Transition-Metal-Catalyzed Processes as Quantified by E Factors. Angew. Chem. Int. Ed. 2013, 52 (42), 10952-10958.

92. Ma, Y.; Liu, H.; Chen, L.; Cui, X.; Zhu, J.; Deng, J., Asymmetric Transfer Hydrogenation of Prochiral Ketones in Aqueous Media with New Water-Soluble Chiral Vicinal Diamine as Ligand. Org. Lett. 2003, 5 (12), 2103-2106.

93. Ahlford, K.; Lind, J.; Mäler, L.; Adolfsson, H., Rhodium-catalyzed asymmetric transfer hydrogenation of alkyl and aryl ketones in aqueous media. Green Chem. 2008, 10 (8), 832835 .

94. Li, J.; Tang, Y.; Wang, Q.; Li, X.; Cun, L.; Zhang, X.; Zhu, J.; Li, L.; Deng, J., Chiral Surfactant-Type Catalyst for Asymmetric Reduction of Aliphatic Ketones in Water. J. Am. Chem. Soc. 2012, 134 (45), 18522-18525.

95. Li, J.; Li, X.; Ma, Y.; Wu, J.; Wang, F.; Xiang, J.; Zhu, J.; Wang, Q.; Deng, J., Surfactant-accelerated asymmetric transfer hydrogenation with recyclable water-soluble catalyst in aqueous media. $R S C A d v$. 2013, 3 (6), 1825-1834.

96. Herrmann, W. A.; Kohlpaintner, C. W., Water-Soluble Ligands, Metal Complexes, and Catalysts: Synergism of Homogeneous and Heterogeneous Catalysis. Angew. Chem. Int. Ed. 1993, 32 (11), 1524-1544.

97. Shaughnessy, K. H., Hydrophilic Ligands and Their Application in Aqueous-Phase Metal-Catalyzed Reactions. Chem. Rev. 2009, 109 (2), 643-710.

98. Grosselin, J. M.; Mercier, C.; Allmang, G.; Grass, F., Selective hydrogenation of .alpha.,.beta.-unsaturated aldehydes in aqueous organic two-phase solvent systems using ruthenium or rhodium complexes of sulfonated phosphines. Organometallics 1991, 10 (7), 2126-2133.

99. Delhomme, C.; Schaper, L.-A.; Zhang-Preße, M.; Raudaschl-Sieber, G.; Weuster-Botz, D.; Kühn, F. E., Catalytic hydrogenation of levulinic acid in aqueous phase. J. Organomet. Chem. 2013, 724, 297-299. 
100. Moustani, C.; Anagnostopoulou, E.; Krommyda, K.; Panopoulou, C.; Koukoulakis, K. G.; Bakeas, E. B.; Papadogianakis, G., Novel aqueous-phase hydrogenation reaction of the key biorefinery platform chemical levulinic acid into $\gamma$-valerolactone employing highly active, selective and stable water-soluble ruthenium catalysts modified with nitrogen-containing ligands. Appl. Catal., B 2018, 238, 82-92.

101. Jessop, P. G.; Ikariya, T.; Noyori, R., Homogeneous Catalysis in Supercritical Fluids. Chem. Rev. 1999, 99 (2), 475-494.

102. Budisa, N.; Schulze-Makuch, D., Supercritical Carbon Dioxide and Its Potential as a Life-Sustaining Solvent in a Planetary Environment. Life 2014, 4 (3), 331.

103. Bhanage, B. M.; Ikushima, Y.; Shirai, M.; Arai, M., The selective formation of unsaturated alcohols by hydrogenation of $\alpha, \beta$-unsaturated aldehydes in supercritical carbon dioxide using unpromoted Pt/Al2O3 catalyst. Catal. Lett. 1999, 62 (2), 175-177.

104. Purwanto; Deshpande, R. M.; Chaudhari, R. V.; Delmas, H., Solubility of Hydrogen, Carbon Monoxide, and 1-Octene in Various Solvents and Solvent Mixtures. J. Chem. Eng. Data 1996, 41 (6), 1414-1417.

105. Moriyoshi, T.; Kita, T.; Uosaki, Y., Static Relative Permittivity of Carbon Dioxide and Nitrous Oxide up to $30 \mathrm{MPa}$. Ber. Bunsenges. Phys. Chem. 1993, 97 (4), 589-596.

106. Zhao, F.; Ikushima, Y.; Shirai, M.; Ebina, T.; Arai, M., Influence of electronic state and dispersion of platinum particles on the conversion and selectivity of hydrogenation of an $\alpha, \beta-$ unsaturated aldehyde in supercritical carbon dioxide. J. Mol. Catal. A: Chem. 2002, 180 (1), 259-265.

107. Liu, R.; Zhao, F.; Fujita, S.-i.; Arai, M., Selective hydrogenation of citral with transition metal complexes in supercritical carbon dioxide. Appl. Catal., A 2007, 316 (2), 127-133.

108. Li, G.; Jiang, H.; Li, J., Use of water as a direct hydrogen donor in supercritical carbon dioxide: a novel and efficient $\mathrm{Zn}-\mathrm{HO}-\mathrm{CO}$ system for selective reduction of aldehydes to alcohols. Green Chem. 2001, 3 (5), 250-251.

109. Kamitanaka, T.; Matsuda, T.; Harada, T., Mechanism for the reduction of ketones to the corresponding alcohols using supercritical 2-propanol. Tetrahedron 2007, 63 (6), 14291434.

110. Daimon, A.; Kamitanaka, T.; Kishida, N.; Matsuda, T.; Harada, T., Selective reduction of unsaturated aldehydes to unsaturated alcohols using supercritical 2-propanol. J. of Supercritical Fluids 2006, 37 (2), 215-219.

111. Egorova, K. S.; Ananikov, V. P., Which Metals are Green for Catalysis? Comparison of the Toxicities of Ni, Cu, Fe, Pd, Pt, Rh, and Au Salts. Angew. Chem. Int. Ed. 2016, 55 (40), 12150-12162.

112. Hayler, J. D.; Leahy, D. K.; Simmons, E. M., A Pharmaceutical Industry Perspective on Sustainable Metal Catalysis. Organometallics 2018.

113. Bauer, I.; Knölker, H.-J., Iron Catalysis in Organic Synthesis. Chem. Rev. 2015, 115 (9), 3170-3387.

114. Knölker, H.-J.; Heber, J.; Mahler, C. H., Transition Metal-Diene Complexes in Organic Synthesis, Part 14.1 Regioselective Iron-Mediated [2+2+1] Cycloadditions of Alkynes and Carbon Monoxide: Synthesis of Substituted Cyclopentadienones. Synlett 1992, 1992 (12), 1002-1004.

115. Knölker, H.-J.; Baum, E.; Goesmann, H.; Klauss, R., Demetalation of Tricarbonyl(cyclopentadienone)iron Complexes Initiated by a Ligand Exchange Reaction with $\mathrm{NaOH}-\mathrm{X}$-Ray Analysis of a Complex with Nearly Square-Planar Coordinated Sodium. Angew. Chem. Int. Ed. 1999, 38 (13-14), 2064-2066. 
116. Johnson, T. C.; Clarkson, G. J.; Wills, M., (Cyclopentadienone)iron Shvo Complexes: Synthesis and Applications to Hydrogen Transfer Reactions. Organometallics 2011, 30 (7), $1859-1868$.

117. Bullock, R. M., An Iron Catalyst for Ketone Hydrogenations under Mild Conditions. Angew. Chem. Int. Ed. 2007, 46 (39), 7360-7363.

118. Casey, C. P.; Guan, H., An Efficient and Chemoselective Iron Catalyst for the Hydrogenation of Ketones. J. Am. Chem. Soc. 2007, 129 (18), 5816-5817.

119. Fleischer, S.; Zhou, S.; Junge, K.; Beller, M., General and Highly Efficient IronCatalyzed Hydrogenation of Aldehydes, Ketones, and $\alpha, \beta$-Unsaturated Aldehydes. Angew. Chem. Int. Ed. 2013, 52 (19), 5120-5124.

120. Morris, R. H., Asymmetric hydrogenation, transfer hydrogenation and hydrosilylation of ketones catalyzed by iron complexes. Chem. Soc. Rev. 2009, 38 (8), 2282-2291.

121. Sui-Seng, C.; Freutel, F.; Lough, A. J.; Morris, R. H., Highly Efficient Catalyst Systems Using Iron Complexes with a Tetradentate PNNP Ligand for the Asymmetric Hydrogenation of Polar Bonds. Angew. Chem. Int. Ed. 2008, 47 (5), 940-943.

122. Mikhailine, A.; Lough, A. J.; Morris, R. H., Efficient Asymmetric Transfer Hydrogenation of Ketones Catalyzed by an Iron Complex Containing a P-N-N-P Tetradentate Ligand Formed by Template Synthesis. J. Am. Chem. Soc. 2009, 131 (4), 1394-1395.

123. Sonnenberg, J. F.; Morris, R. H., Distinguishing homogeneous from nanoparticle asymmetric iron catalysis. Catal. Sci. Technol. 2014, 4 (10), 3426-3438.

124. Sonnenberg, J. F.; Coombs, N.; Dube, P. A.; Morris, R. H., Iron Nanoparticles Catalyzing the Asymmetric Transfer Hydrogenation of Ketones. J. Am. Chem. Soc. 2012, 134 (13), 5893-5899.

125. Li, J.; Liu, J. 1.; Zhou, H. j.; Fu, Y., Catalytic Transfer Hydrogenation of Furfural to Furfuryl Alcohol over Nitrogen-Doped Carbon-Supported Iron Catalysts. ChemSusChem 2016, 9 (11), 1339-1347.

126. Garbe, M.; Junge, K.; Beller, M., Homogeneous Catalysis by Manganese-Based Pincer Complexes. Eur. J. Org. Chem. 2017, 2017 (30), 4344-4362.

127. Kallmeier, F.; Irrgang, T.; Dietel, T.; Kempe, R., Highly Active and Selective Manganese $\mathrm{C}=\mathrm{O}$ Bond Hydrogenation Catalysts: The Importance of the Multidentate Ligand, the Ancillary Ligands, and the Oxidation State. Angew. Chem. Int. Ed. 2016, 55 (39), 1180611809.

128. Glatz, M.; Stöger, B.; Himmelbauer, D.; Veiros, L. F.; Kirchner, K., Chemoselective Hydrogenation of Aldehydes under Mild, Base-Free Conditions: Manganese Outperforms Rhenium. ACS Catal. 2018, 8 (5), 4009-4016.

129. Wei, D.; Bruneau-Voisine, A.; Chauvin, T.; Dorcet, V.; Roisnel, T.; Valyaev, D. A.; Lugan, N.; Sortais, J.-B., Hydrogenation of Carbonyl Derivatives Catalysed by Manganese Complexes Bearing Bidentate Pyridinyl-Phosphine Ligands. Adv. Synth. Catal. 2018, 360 (4), 676-681.

130. Elangovan, S.; Topf, C.; Fischer, S.; Jiao, H.; Spannenberg, A.; Baumann, W.; Ludwig, R.; Junge, K.; Beller, M., Selective Catalytic Hydrogenations of Nitriles, Ketones, and Aldehydes by Well-Defined Manganese Pincer Complexes. J. Am. Chem. Soc. 2016, 138 (28), 8809-8814.

131. Perez, M.; Elangovan, S.; Spannenberg, A.; Junge, K.; Beller, M., Molecularly Defined Manganese Pincer Complexes for Selective Transfer Hydrogenation of Ketones. ChemSusChem 2017, 10 (1), 83-86.

132. Bruneau-Voisine, A.; Wang, D.; Dorcet, V.; Roisnel, T.; Darcel, C.; Sortais, J.-B., Transfer Hydrogenation of Carbonyl Derivatives Catalyzed by an Inexpensive Phosphine-Free Manganese Precatalyst. Org. Lett. 2017, 19 (13), 3656-3659. 
133. Martínez-Ferraté, O.; Werlé, C.; Franciò, G.; Leitner, W., Aminotriazole Mn(I) Complexes as Effective Catalysts for Transfer Hydrogenation of Ketones. ChemCatChem 2018, 10 (20), 4514-4518.

134. Le Page, M. D.; James, B. R., Nickel bromide as a hydrogen transfer catalyst. Chem. Commun. 2000, (17), 1647-1648.

135. Phukan, P.; Sudalai, A., Chemoselective Transfer Hydrogenation of Carbonyl Compounds Catalyzed by Macrocyclic Nickel (II) Complex. Synth. Comm. 2000, 30 (13), 2401-2405.

136. Iyer, S.; Varghese, J. P., [NiCl2(PPh3)2] catalysed transfer hydrogenation of ketones and aldehydes by propan-2-ol. J. Chem. Soc., Chem. Commun 1995, (4), 465-466.

137. Alonso, F.; Riente, P.; Yus, M., Hydrogen-transfer reduction of carbonyl compounds promoted by nickel nanoparticles. Tetrahedron 2008, 64 (8), 1847-1852.

138. T. Upadhya, T.; P. Katdare, S.; P. Sabde, D.; Ramaswamy, V.; Sudalai, A., Chemoselective transfer hydrogenation of nitroarenes, aldehydes and ketones with propan-2ol catalysed by Ni-stabilized zirconia. Chem. Commun. 1997, (12), 1119-1120.

139. Mebane, R. C.; Holte, K. L.; Gross, B. H., Transfer Hydrogenation of Ketones with 2Propanol and Raney® Nickel. Synth. Comm. 2007, 37 (16), 2787-2791.

140. Shimura, K.; Shimizu, K.-i., Transfer hydrogenation of ketones by ceria-supported Ni catalysts. Green Chem. 2012, 14 (11), 2983-2985.

141. Alonso, F.; Riente, P.; Yus, M., Hydrogen-transfer reduction of carbonyl compounds catalysed by nickel nanoparticles. Tetrahedron Lett. 2008, 49 (12), 1939-1942.

142. Escande, V.; Poullain, C.; Clavé, G.; Petit, E.; Masquelez, N.; Hesemann, P.; Grison, C., Bio-based and environmental input for transfer hydrogenation using EcoNi(0) catalyst in isopropanol. Appl. Catal., B 2017, 210, 495-503.

143. Hudson, R.; Feng, Y.; Varma, R. S.; Moores, A., Bare magnetic nanoparticles: sustainable synthesis and applications in catalytic organic transformations. Green Chem. 2014, 16 (10), 4493-4505.

144. Kantam, M. L.; Yadav, J.; Laha, S.; Srinivas, P.; Sreedhar, B.; Figueras, F., Asymmetric Hydrosilylation of Ketones Catalyzed by Magnetically Recoverable and Reusable Copper Ferrite Nanoparticles. J. Org. Chem. 2009, 74 (12), 4608-4611.

145. Dasgupta, S.; Chakraborty, A.; Chatterjee, S.; Chattopadhyay, T., Synthesis and characterization of magnetically separable Fe3O4@AHBA@Ni(0) [AHBA=3-amino-4hydroxybenzoicacid] nanocatalyst: Applications for carbonyl hydrogenation and alcohol oxidation. Inorg. Chim. Acta 2018, 474, 1-10.

146. Hudson, R.; Chazelle, V.; Bateman, M.; Roy, R.; Li, C.-J.; Moores, A., Sustainable Synthesis of Magnetic Ruthenium-Coated Iron Nanoparticles and Application in the Catalytic Transfer Hydrogenation of Ketones. ACS Sustainable Chem. Eng. 2015, 3 (5), 814-820.

147. Li, A. Y.; Kaushik, M.; Li, C.-J.; Moores, A., Microwave-Assisted Synthesis of Magnetic Carboxymethyl Cellulose-Embedded Ag-Fe3O4 Nanocatalysts for Selective Carbonyl Hydrogenation. ACS Sustainable Chem. Eng. 2016, 4 (3), 965-973.

148. Stephan, D. W., The broadening reach of frustrated Lewis pair chemistry. Science 2016, 354 (6317).

149. Scott, D. J.; Fuchter, M. J.; Ashley, A. E., Designing effective 'frustrated Lewis pair' hydrogenation catalysts. Chem. Soc. Rev. 2017, 46 (19), 5689-5700.

150. Welch, G. C.; Juan, R. R. S.; Masuda, J. D.; Stephan, D. W., Reversible, Metal-Free Hydrogen Activation. Science 2006, 314 (5802), 1124-1126.

151. Mahdi, T.; Stephan, D. W., Enabling Catalytic Ketone Hydrogenation by Frustrated Lewis Pairs. J. Am. Chem. Soc. 2014, 136 (45), 15809-15812. 
152. Mahdi, T.; Stephan, D. W., Facile Protocol for Catalytic Frustrated Lewis Pair Hydrogenation and Reductive Deoxygenation of Ketones and Aldehydes. Angew. Chem. Int. Ed. 2015, 54 (29), 8511-8514.

153. Scott, D. J.; Fuchter, M. J.; Ashley, A. E., Nonmetal Catalyzed Hydrogenation of Carbonyl Compounds. J. Am. Chem. Soc. 2014, 136 (45), 15813-15816.

154. Scott, D. J.; Simmons, T. R.; Lawrence, E. J.; Wildgoose, G. G.; Fuchter, M. J.; Ashley, A. E., Facile Protocol for Water-Tolerant "Frustrated Lewis Pair"-Catalyzed Hydrogenation. ACS Catal. 2015, 5 (9), 5540-5544.

155. Das, S.; Pati, S. K., On the Mechanism of Frustrated Lewis Pair Catalysed Hydrogenation of Carbonyl Compounds. Chem. Eur. J. 2017, 23 (5), 1078-1085.

156. Krempner, C.; Mummadi, S.; Brar, A.; Wang, G.; Kenefake, D.; Diaz, R.; Unruh, D.; Li, S., 'Inverse' Frustrated Lewis Pairs - An Inverse FLP Approach to the Catalytic Metal Free Hydrogenation of Ketones. Chem. Eur. J. 2018, 24 (62), 16526-16531.

157. Primo, A.; Neatu, F.; Florea, M.; Parvulescu, V.; Garcia, H., Graphenes in the absence of metals as carbocatalysts for selective acetylene hydrogenation and alkene hydrogenation. Nat. Commun. 2014, 5, 5291.

158. Trandafir, M.-M.; Florea, M.; Neaţu, F.; Primo, A.; Parvulescu, V. I.; García, H., Graphene from Alginate Pyrolysis as a Metal-Free Catalyst for Hydrogenation of Nitro Compounds. ChemSusChem 2016, 9 (13), 1565-1569.

159. Hunt, A. J.; Matharu, A. S.; King, A. H.; Clark, J. H., The importance of elemental sustainability and critical element recovery. Green Chem. 2015, 17 (4), 1949-1950.

160. Hu, Q.; Yang, L.; Fan, G.; Li, F., Hydrogenation of biomass-derived compounds containing a carbonyl group over a copper-based nanocatalyst: Insight into the origin and influence of surface oxygen vacancies. J. Catal. 2016, 340, 184-195.

161. Mehnert, C. P., Supported Ionic Liquid Catalysis. Chem. Eur. J. 2005, 11 (1), 50-56.

162. Štefane, B.; Požgan, F., Metal-Catalysed Transfer Hydrogenation of Ketones. Top. Curr. Chem. 2016, 374 (2), 18.

163. Trost, B., The atom economy--a search for synthetic efficiency. Science 1991, 254 (5037), 1471-1477.

164. Wang, D.; Astruc, D., The Golden Age of Transfer Hydrogenation. Chem. Rev. 2015, 115 (13), 6621-6686.

165. G. Hitzler, M.; Poliakoff, M., Continuous hydrogenation of organic compounds in supercritical fluids. Chem. Commun. 1997, (17), 1667-1668.

166. Brieger, G.; Nestrick, T. J., Catalytic transfer hydrogenation. Chem. Rev. 1974, 74 (5), 567-580.

167. Sordakis, K.; Tang, C.; Vogt, L. K.; Junge, H.; Dyson, P. J.; Beller, M.; Laurenczy, G., Homogeneous Catalysis for Sustainable Hydrogen Storage in Formic Acid and Alcohols. Chem. Rev. 2018, 118 (2), 372-433.

168. Schlesinger, H. I.; Brown, H. C.; Finholt, A. E., The Preparation of Sodium Borohydride by the High Temperature Reaction of Sodium Hydride with Borate Esters. J. Am. Chem. Soc. 1953, 75 (1), 205-209.

169. Finholt, A. E.; Bond, A. C.; Schlesinger, H. I., Lithium Aluminum Hydride, Aluminum Hydride and Lithium Gallium Hydride, and Some of their Applications in Organic and Inorganic Chemistry. J. Am. Chem. Soc. 1947, 69 (5), 1199-1203.

170. Holger, E.; Christian, F.; Gerd, B.; Sjoerd, H., LiAlH4: From Stoichiometric Reduction to Imine Hydrogenation Catalysis. Angew. Chem. Int. Ed. 2018, 57 (24), 7156-7160.

171. Manna, S.; Antonchick, A. P., Catalytic Transfer Hydrogenation Using Biomass as Hydrogen Source. ChemSusChem 0 (ja). 
172. Guyon, C.; Métay, E.; Duguet, N.; Lemaire, M., Biphasic Glycerol/2-MeTHF, Ruthenium-Catalysed Enantioselective Transfer Hydrogenation of Ketones Using Sodium Hypophosphite as Hydrogen Donor. Eur. J. Org. Chem. 2013, 2013 (24), 5439-5444.

173. Cha, J. S., Recent Developments In Meerwein-Ponndorf-Verley and Related Reactions for the Reduction of Organic Functional Groups Using Aluminum, Boron, and Other Metal Reagents: A Review. Org. Proc. Res. Dev. 2006, 10 (5), 1032-1053.

174. Verley, A., Exchange of functional groups between two molecules. Exchange of alcohol and aldehyde groups. Bull. Soc. Chim. Fr. 1925, 37, 871.

175. Hans, M.; Rudolf, S., Ein neues Verfahren zur Reduktion von Aldehyden und Ketonen. Liebigs Ann. 1925, 444 (1), 221-238.

176. Wolfgang, P., Der reversible Austausch der Oxydationsstufen zwischen Aldehyden oder Ketonen einerseits und primären oder sekundären Alkoholen anderseits. Angew. Chem. 1926, 39 (5), 138-143.

177. Akamanchi, K. G.; Noorani, V. R., Truly catalytic Meerwein-Ponndorf-Verley (MPV) reduction. Tetrahedron Lett. 1995, 36 (28), 5085-5088.

178. Akamanchi, K. G.; Varalakshmy, N. R., Aluminium isopropoxide - TFA, a modified catalyst for highly accelerated meerwein - ponndorf - verley (MPV) reduction. Tetrahedron Lett. 1995, 36 (20), 3571-3572.

179. Ooi, T.; Miura, T.; Itagaki, Y.; Ichikawa, H.; Maruoka, K., Catalytic MeerweinPonndorf-Verley (MPV) and Oppenauer (OPP) Reactions: Remarkable Acceleration of the Hydride Transfer by Powerful Bidentate Aluminum Alkoxides. Synthesis 2002, 2002 (02), 0279-0291.

180. Konishi, K.; Makita, K.; Aida, T.; Inoue, S., Highly stereoselective hydrogen transfer from alcohols to carbonyl compounds catalysed by aluminium porphyrins. J. Chem. Soc., Chem. Commun 1988, (10), 643-645.

181. McNerney, B.; Whittlesey, B.; Cordes, D. B.; Krempner, C., A Well-Defined Monomeric Aluminum Complex as an Efficient and General Catalyst in the MeerweinPonndorf-Verley Reduction. Chem. Eur. J. 2014, 20 (46), 14959-14964.

182. López-Asensio, R.; Cecilia, J. A.; Jiménez-Gómez, C. P.; García-Sancho, C.; MorenoTost, R.; Maireles-Torres, P., Selective production of furfuryl alcohol from furfural by catalytic transfer hydrogenation over commercial aluminas. Appl. Catal., A 2018, 556, 1-9.

183. He, J.; Li, H.; Lu, Y.-M.; Liu, Y.-X.; Wu, Z.-B.; Hu, D.-Y.; Yang, S., Cascade catalytic transfer hydrogenation-cyclization of ethyl levulinate to $\gamma$-valerolactone with $\mathrm{Al}-\mathrm{Zr}$ mixed oxides. Appl. Catal., A 2016, 510, 11-19.

184. Chia, M.; Dumesic, J. A., Liquid-phase catalytic transfer hydrogenation and cyclization of levulinic acid and its esters to $\gamma$-valerolactone over metal oxide catalysts. Chem. Commun. 2011, 47 (44), 12233-12235.

185. Wang, J.; Jaenicke, S.; Chuah, G.-K., Zirconium-Beta zeolite as a robust catalyst for the transformation of levulinic acid to $\gamma$-valerolactone via Meerwein-Ponndorf-Verley reduction. $R S C A d v$. 2014, 4 (26), 13481-13489.

186. Li, F.; France, L. J.; Cai, Z.; Li, Y.; Liu, S.; Lou, H.; Long, J.; Li, X., Catalytic transfer hydrogenation of butyl levulinate to $\gamma$-valerolactone over zirconium phosphates with adjustable Lewis and Brønsted acid sites. Appl. Catal., B 2017, 214, 67-77.

187. Valekar, A. H.; Cho, K.-H.; Chitale, S. K.; Hong, D.-Y.; Cha, G.-Y.; Lee, U. H.; Hwang, D. W.; Serre, C.; Chang, J.-S.; Hwang, Y. K., Catalytic transfer hydrogenation of ethyl levulinate to $\gamma$-valerolactone over zirconium-based metal-organic frameworks. Green Chem. 2016, 18 (16), 4542-4552.

188. Song, J.; Wu, L.; Zhou, B.; Zhou, H.; Fan, H.; Yang, Y.; Meng, Q.; Han, B., A new porous $\mathrm{Zr}$-containing catalyst with a phenate group: an efficient catalyst for the catalytic 
transfer hydrogenation of ethyl levulinate to $\gamma$-valerolactone. Green Chem. 2015, 17 (3), 16261632.

189. Assary, R. S.; Curtiss, L. A.; Dumesic, J. A., Exploring Meerwein-Ponndorf-Verley Reduction Chemistry for Biomass Catalysis Using a First-Principles Approach. ACS Catal. 2013, 3 (12), 2694-2704.

190. Ouali, A.; Majoral, J.-P.; Caminade, A.-M.; Taillefer, M., NaOH-Promoted Hydrogen Transfer: Does $\mathrm{NaOH}$ or Traces of Transition Metals Catalyze the Reaction? ChemCatChem 2009, 1 (4), 504-509.

191. Polshettiwar, V.; Varma, R. S., Revisiting the Meerwein-Ponndorf-Verley reduction: a sustainable protocol for transfer hydrogenation of aldehydes and ketones. Green Chem. 2009, 11 (9), 1313-1316.

192. Hietala, J.; Vuori, A.; Johnsson, P.; Pollari, I.; Reutemann, W.; Kieczka, H., Formic Acid. In Ullmann's Encyclopedia of Industrial Chemistry, Wiley-VCH, Ed. 2016.

193. Kumar, B.; Llorente, M.; Froehlich, J.; Dang, T.; Sathrum, A.; Kubiak, C. P., Photochemical and Photoelectrochemical Reduction of CO2. Annu. Rev. Phys. Chem. 2012, 63 (1), 541-569.

194. Liu, X.; Li, S.; Liu, Y.; Cao, Y., Formic acid: A versatile renewable reagent for green and sustainable chemical synthesis. Chin. J. Catal. 2015, 36 (9), 1461-1475.

195. Ariger, M. A.; Carreira, E. M., pH-Independent Transfer Hydrogenation in Water: Catalytic, Enantioselective Reduction of $\beta$-Keto Esters. Org. Lett. 2012, 14 (17), 4522-4524.

196. Wu, X.; Li, X.; Hems, W.; King, F.; Xiao, J., Accelerated asymmetric transfer hydrogenation of aromatic ketones in water. Org. Biomol. Chem. 2004, 2 (13), 1818-1821.

197. Soltani, O.; Ariger, M. A.; Vázquez-Villa, H.; Carreira, E. M., Transfer Hydrogenation in Water: Enantioselective, Catalytic Reduction of $\alpha$-Cyano and $\alpha$-Nitro Substituted Acetophenones. Org. Lett. 2010, 12 (13), 2893-2895.

198. Seashore-Ludlow, B.; Saint-Dizier, F.; Somfai, P., Asymmetric Transfer Hydrogenation Coupled with Dynamic Kinetic Resolution in Water: Synthesis of anti- $\beta$ Hydroxy- $\alpha$-amino Acid Derivatives. Org. Lett. 2012, 14 (24), 6334-6337.

199. Zheng, L.-S.; Llopis, Q.; Echeverria, P.-G.; Férard, C.; Guillamot, G.; Phansavath, P.; Ratovelomanana-Vidal, V., Asymmetric Transfer Hydrogenation of (Hetero)arylketones with Tethered Rh(III)-N-(p-Tolylsulfonyl)-1,2-diphenylethylene-1,2-diamine Complexes: Scope and Limitations. J. Org. Chem. 2017, 82 (11), 5607-5615.

200. Gröger, H.; Hummel, W.; Buchholz, S.; Drauz, K.; Nguyen, T. V.; Rollmann, C.; Hüsken, H.; Abokitse, K., Practical Asymmetric Enzymatic Reduction through Discovery of a Dehydrogenase-Compatible Biphasic Reaction Media. Org. Lett. 2003, 5 (2), 173-176.

201. Xian-Long, D.; Lin, H.; She, Z.; Yong-Mei, L.; Yong, C.; He-Yong, H.; Kang-Nian, F., Hydrogen-independent reductive transformation of carbohydrate biomass into $\gamma$ valerolactone and pyrrolidone derivatives with supported gold catalysts. Angew. Chem. Int. Ed. 2011, 50 (34), 7815-7819.

202. Fu, M.-C.; Shang, R.; Huang, Z.; Fu, Y., Conversion of Levulinate Ester and Formic Acid into $\gamma$-Valerolactone Using a Homogeneous Iron Catalyst. Synlett 2014, 25 (19), 27482752.

203. Mohan, V.; David, R. B.; Rama, R. K. S.; B., J. S.; E., v. Z. W., Hydrogenation of Levulinic Acid Using Formic Acid as a Hydrogen Source over Ni/SiO2 Catalysts. Chem. Eng. Tech. 2017, 40 (4), 719-726.

204. García, J. I.; García-Marín, H.; Pires, E., Glycerol based solvents: synthesis, properties and applications. Green Chem. 2014, 16 (3), 1007-1033. 
205. Díaz-Álvarez, A.; Cadierno, V., Glycerol: A promising Green Solvent and Reducing Agent for Metal-Catalyzed Transfer Hydrogenation Reactions and Nanoparticles Formation. Appl. Sci. 2013, 3 (1), 55.

206. Tavor, D.; Sheviev, O.; Dlugy, C.; Wolfson, A., Transfer hydrogenations of benzaldehyde using glycerol as solvent and hydrogen source. Can. J. Chem. 2010, 88 (4), 305308.

207. Azua, A.; Mata, J. A.; Peris, E., Iridium NHC Based Catalysts for Transfer Hydrogenation Processes Using Glycerol as Solvent and Hydrogen Donor. Organometallics 2011, 30 (20), 5532-5536.

208. Sharma, A. K.; Joshi, H.; Sharma, K. N.; Gupta, P. L.; Singh, A. K., 2-Propanol vs Glycerol as Hydrogen Source in Catalytic Activation of Transfer Hydrogenation with ( $\eta 6-$ Benzene)ruthenium(II) Complexes of Unsymmetrical Bidentate Chalcogen Ligands. Organometallics 2014, 33 (13), 3629-3639.

209. Gawande, M. B.; Rathi, A. K.; Branco, P. S.; Nogueira, I. D.; Velhinho, A.; Shrikhande, J. J.; Indulkar, U. U.; Jayaram, R. V.; Ghumman, C. A. A.; Bundaleski, N.; Teodoro, O. M. N. D., Regio- and Chemoselective Reduction of Nitroarenes and Carbonyl Compounds over Recyclable Magnetic Ferrite-Nickel Nanoparticles (Fe3O4-Ni) by Using Glycerol as a Hydrogen Source. Chem. Eur. J. 2012, 18 (40), 12628-12632.

210. Sauer, R. O.; Scheiber, W. J.; Brewer, S. D., Derivatives of the Methylchlorosilanes. V. Polysiloxanes from Methyldichlorosilane. J. Am. Chem. Soc. 1946, 68 (6), 962-963.

211. J. Lawrence, N.; D. Drew, M.; M. Bushell, S., Polymethylhydrosiloxane: a versatile reducing agent for organic synthesis. J. Chem. Soc., Perkin Trans. 1, 1999, (23), 3381-3391.

212. Döhlert, P.; Enthaler, S., Conversion of Poly(methylhydrosiloxane) Waste to Useful Commodities. Catal. Lett. 2016, 146 (2), 345-352.

213. Lipowitz, J.; Bowman, S. A., Use of polymethylhydrosiloxane as a selective, neutral reducing agent for aldehydes, ketones, olefins, and aromatic nitro compounds. J. Org. Chem. 1973, 38 (1), 162-165.

214. Grady, G. L.; Kuivila, H. G., Simple technique for performing reactions with organotin hydrides. J. Org. Chem. 1969, 34 (6), 2014-2016.

215. Lawrence, N. J.; Bushell, S. M., An efficient protocol for the reduction of ketones with tin(II) complexes and PMHS. Tetrahedron Lett. 2000, 41 (22), 4507-4512.

216. Kobayashi, Y.; Takahisa, E.; Nakano, M.; Watatani, K., Reduction of carbonyl compounds by using polymethylhydro-siloxane: reactivity and selectivity. Tetrahedron 1997, 53 (5), 1627-1634.

217. Wang, Z.; Wroblewski, A. E.; Verkade, J. G., P(MeNCH2CH2)3N: An Efficient Promoter for the Reduction of Aldehydes and Ketones with Poly(methylhydrosiloxane). $J$. Org. Chem. 1999, 64 (21), 8021-8023.

218. Kseniya, R.; I., N. G., Base-Catalyzed Hydrosilylation of Ketones and Esters and Insight into the Mechanism. Chem. Eur. J. 2014, 20 (3), 839-845.

219. Misal, C. L. C.; David, B.; Jean-Baptiste, S.; Christophe, D., Iron dihydride complex as the pre-catalyst for efficient hydrosilylation of aldehydes and ketones under visible light activation. Adv. Synth. Catal. 2011, 353 (8), 1279-1284.

220. Elina, B.; Lorenzo, Z.; Hans, A., Selective hydrosilylation of ketones catalyzed by in situ-generated iron NHC complexes. Appl. Organomet. Chem. 2011, 25 (10), 748-752.

221. Daniele, A.; Nadim, S.; Shaolin, Z.; Shoubhik, D.; Kathrin, J.; Matthias, B., Chemoand Stereoselective Iron-Catalyzed Hydrosilylation of Ketones. Chem. Asian J. 2010, 5 (7), 1687-1691.

222. Marcin, S.; Agata, B.; Jacek, M., Zinc-Catalyzed Enantioselective Hydrosilylation of Ketones and Imines under Solvent-Free Conditions. ChemCatChem 2016, 8 (23), 3575-3579. 
223. Mimoun, H., Selective Reduction of Carbonyl Compounds by Polymethylhydrosiloxane in the Presence of Metal Hydride Catalysts. J. Org. Chem. 1999, 64 (7), 2582-2589.

224. Bette, V.; Mortreux, A.; Savoia, D.; Carpentier, J.-F., New developments in zinccatalyzed asymmetric hydrosilylation of ketones with PMHS. Tetrahedron 2004, 60 (12), 2837-2842.

225. Mimoun, H.; de Saint Laumer, J. Y.; Giannini, L.; Scopelliti, R.; Floriani, C., Enantioselective Reduction of Ketones by Polymethylhydrosiloxane in the Presence of Chiral Zinc Catalysts. J. Am. Chem. Soc. 1999, 121 (26), 6158-6166.

226. Cravotto, G.; Gaudino, E. C., CHAPTER 3 Oxidation and Reduction by Solid Oxidants and Reducing Agents using Ball-Milling. In Ball Milling Towards Green Synthesis: Applications, Projects, Challenges, The Royal Society of Chemistry: 2015; pp 58-80. 